\title{
Mechanisms of Assortative Mating in Speciation with Gene Flow: Connecting Theory and Empirical Research
}

\author{
Michael Kopp, ${ }^{1, \star}, \dagger$ Maria R. Servedio, ${ }^{2, \star}$ Tamra C. Mendelson, ${ }^{3}$ Rebecca J. Safran, ${ }^{4}$ \\ Rafael L. Rodríguez, ${ }^{5}$ Mark E. Hauber, ${ }^{6}$ Elizabeth C. Scordato, ${ }^{4}$ Laurel B. Symes, ${ }^{7}$ \\ Christopher N. Balakrishnan, ${ }^{8}$ David M. Zonana, ${ }^{4}$ and G. Sander van Doorn ${ }^{9}$
}

\begin{abstract}
1. Aix Marseille Université, CNRS, Centrale Marseille, I2M, 3 Place Victor Hugo, 13331 Marseille Cedex 3, France; 2. Department of Biology, University of North Carolina, Chapel Hill, North Carolina 27599; 3. Department of Biological Sciences, University of Maryland Baltimore County, Baltimore, Maryland 21250; 4. Department of Ecology and Evolutionary Biology, University of Colorado, Boulder, Colorado 80309; 5. Behavioral and Molecular Ecology Group, Department of Biological Sciences, University of Wisconsin, Milwaukee, Wisconsin 53201; 6. Department of Animal Biology, School of Integrative Biology, University of Illinois, Urbana, Illinois 61801; 7. Department of Biological Sciences and Department of Psychological and Brain Sciences, Dartmouth College, Hanover, New Hampshire 03755; 8. Department of Biology, East Carolina University, Greenville, North Carolina 27858; 9. Groningen Institute for Evolutionary Life Sciences, University of Groningen, Groningen, The Netherlands
\end{abstract}

Submitted January 29, 2017; Accepted August 17, 2017; Electronically published November 21, 2017

Aв STRACT: The large body of theory on speciation with gene flow has brought to light fundamental differences in the effects of two types of mating rules on speciation: preference/trait rules, in which divergence in both (female) preferences and (male) mating traits is necessary for assortment, and matching rules, in which individuals mate with like individuals on the basis of the presence of traits or alleles that they have in common. These rules can emerge from a variety of behavioral or other mechanisms in ways that are not always obvious. We discuss the theoretical properties of both types of rules and explain why speciation is generally thought to be more likely under matching rather than preference/trait rules. We furthermore discuss whether specific assortative mating mechanisms fall under a preference/trait or matching rule, present empirical evidence for these mechanisms, and propose empirical tests that could distinguish between them. The synthesis of the theoretical literature on these assortative mating rules with empirical studies of the mechanisms by which they act can provide important insights into the occurrence of speciation with gene flow. Finally, by providing a clear framework we hope to inspire greater alignment in the ways that both theoreticians and empiricists study mating rules and how these rules affect speciation through maintaining or eroding barriers to gene flow among closely related species or populations.

\footnotetext{
* These authors served as lead authors for the project and contributed equally.

$\dagger$ Corresponding author; e-mail: michael.kopp@univ-amu.fr. ORCIDs: Kopp, http://orcid.org/0000-0001-9444-1947; Servedio, http://orcid .org/0000-0002-3965-4445; Safran, http://orcid.org/0000-0002-4762-2638; Scordato, http://orcid.org/0000-0003-0224-8280; Symes, http://orcid.org/0000-0001-6650 -3813; Balakrishnan, http://orcid.org/0000-0002-0788-0659; Hauber, http://orcid .org/0000-0003-2014-4928; Zonana, http://orcid.org/0000-0002-1599-8913; van Doorn, http://orcid.org/0000-0002-4703-3788.
}

Am. Nat. 2018. Vol. 191, pp. 1-20. (c) 2017 by The University of Chicago. 0003-0147/2018/19101-57518\$15.00. All rights reserved.

DOI: $10.1086 / 694889$
Keywords: assortative mating, speciation with gene flow, mating preferences, sexual selection, imprinting, self-referent phenotype matching.

\section{Introduction}

In the past 2 decades, speciation research - both theoretical and empirical - has recognized the importance of two related issues: the role of divergent natural selection in driving population differentiation (ecological speciation; Rundle and Nosil 2005; Schluter 2009; Nosil 2012; Safran et al. 2013) and the possibility that such divergence can result in speciation in the presence of gene flow (speciation with gene flow; Rice and Hostert 1993; Smadja and Butlin 2011). A number of studies have demonstrated that speciation without complete geographic isolation might be more common than previously thought (e.g., Kirkpatrick and Ravigné 2002; Servedio and Noor 2003; Hey 2006; Bolnick and Fitzpatrick 2007; Mallet 2008; Nosil 2008; Papadopulos et al. 2011). The possible prevalence of speciation with gene flow poses a theoretical challenge because gene flow homogenizes populations and thus opposes divergence and, eventually, speciation. A large number of theoretical models have therefore attempted to analyze the conditions under which speciation with gene flow-including sympatric speciation, parapatric speciation, and reinforcement after secondary contact - is feasible (reviewed in Servedio and Noor 2003; Dieckmann et al. 2004; Gavrilets 2004; Bolnick and Fitzpatrick 2007; Weissing et al. 2011). Many of these models assume that hybrids between incipient species have reduced fitness because of either intrinsic genetic incompatibilities or ecologically based divergent or disruptive selection. Without complete postzygotic isolation, however, 
speciation often requires that gene flow is reduced because of the presence or evolution of some form of assortative mating (any premating mechanism whereby like mates with like, such that mated pairs have positively correlated phenotypes or genotypes; Jiang et al. 2013).

There are numerous biological mechanisms that can bring about assortative mating (and hence premating isolation). Prominent speciation books (e.g., Coyne and Orr 2004) and evolution textbooks (e.g., Futuyma 1998; Zimmer and Emlen 2013), for example, characterize premating isolation by whether it occurs because of habitat choice, temporal isolation, or mate choice. Mate choice mechanisms, in turn, can be subdivided into those based on genetically encoded preferences, sexually imprinted preferences, choosy individuals attempting to match their own trait, or even mechanical constraints (such as chirality in snails; e.g., Gittenberger 1988). While it is tempting to group assortative mating mechanisms by characteristics that make them seem superficially similar, such a classification may not be the most relevant one for the process of speciation. For example, female mate choice based on genetically encoded preferences for particular male traits seems similar to mate choice based on sexual imprinting by daughters on paternal traits and very different from mating in a preferred habitat. Yet the theoretical models discussed below show that mate choice based on imprinting shares fundamental properties with habitat choice, which causes the two mechanisms to behave similarly during speciation and very differently from mate choice based on genetically encoded preferences.

In this article, we first present well-established results from the theoretical literature, which make it clear that there are two prominent types of assortative mating rules with fundamentally different effects on speciation with gene flow: choosy individuals may mate assortatively if they either (1) prefer mates with certain trait values (e.g., of display traits), regardless of the trait values the chooser carries itself (i.e., use a preference/trait rule), or (2) mate on the basis of a match with their own phenotype (i.e., use a matching rule; these rules have also been called similarity-based rules; see Gavrilets 2004). We then discuss the fact that this categorization is rarely applied to empirical systems and present potential solutions for this disconnect. We also discuss novel questions that empirical findings regarding these mechanisms pose for theoretical research. While the topic of this article is the contribution of mating rules to speciation in the presence of gene flow, we do not exclude that parts of the speciation process may proceed in allopatry (e.g., in situations of reinforcement or with dynamically fluctuating environments; see Aguilée et al. 2011). Throughout, our focus is on mate choice behavior in animals, even though some of the mechanisms we discuss may also apply to plants. By synthesizing empirical approaches (what mechanisms of assortative mating are found in nature?) with theoretical ones (what do these mech- anisms of assortative mating imply for the ease of speciation, and why?), we give insight into how the field can progress toward determining the behavioral mechanisms involved in mate choice, their genetic basis, and the consequences for the likelihood of speciation.

\section{Two Types of Assortative Mating Rules Used in Theoretical Investigations of Speciation with Gene Flow}

In the following, we discuss typical scenarios analyzed in theoretical models of speciation with gene flow, focusing on two types of mating rules that are the most conceptually predominant: preference/trait rules and matching rules. We note that not all cases of assortative mating may fit into one of these two categories (see below for one notable exception). Key examples are illustrated in figures 1 and 2, and a comprehensive summary is provided in table 1.

\section{Preference/Trait Rules of Assortative Mating}

Preference/trait rules are a standard tenet of sexual selection theory (Fisher 1930; Lande 1981; Kirkpatrick 1982; Iwasa and Pomiankowski 1999), but in models of speciation with gene flow, they have been less frequently used than matching rules (see below). Speciation models with a preference/trait rule typically consider - explicitly or implicitly — up to four categories of traits (e.g., Doebeli 2005): mating traits (i.e., signals; $\mathrm{T})$, mate preferences $(\mathrm{P})$, choosiness $(\mathrm{C})$, and ecologically selected traits (E; see figs. $1 a, 2 a$; table 1 ). Each of these categories might contain multiple discrete or continuous traits, which are controlled by single or multiple loci, and may be at least partially environmentally determined. For the ease of discussion, we concentrate throughout on the case of a single discrete locus in each category, but the principles are readily generalizable.

The first category of traits (T) consists of mating traits, which are used by the choosy individuals as the basis of mate choice (from now on we will refer to choosy individuals as females for simplicity). Typical examples are male sexual signals, such as colorful ornaments, songs, or pheromones (sometimes referred to in the theoretical literature as marker traits; e.g., red and blue chest color in fig. 1a). Also included are mechanical or biochemical traits that interact with a counterpart in the female, such as copulatory organs or gamete recognition proteins. In sexually dimorphic species, females often do not express the mating trait, even though they carry and pass on alleles for this trait to their offspring. Assortative mating (e.g., due to female preferences in linkage disequilibrium with the trait; see below) can then still be defined as a positive correlation between males and females at the genetic level.

The second and third categories of traits-preferences $\mathrm{P}$ and choosiness $\mathrm{C}$ - describe key aspects of female mate choice 


\section{a}

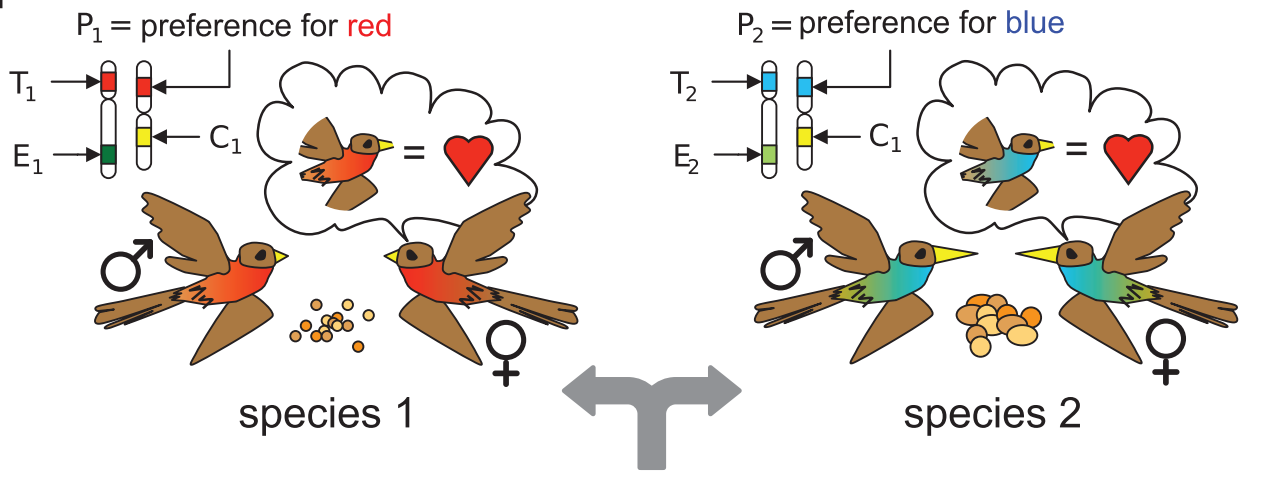

b

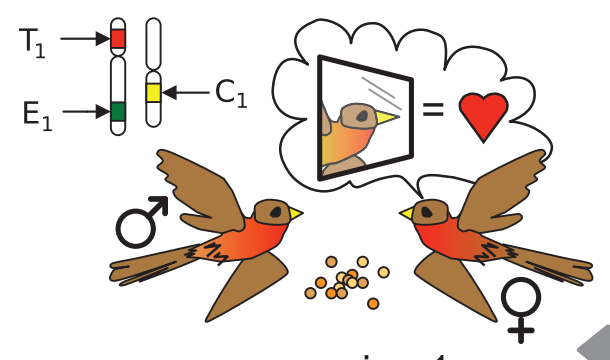

species 1

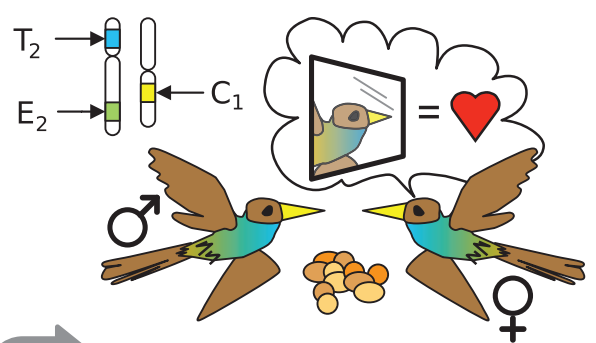

species 2

\section{C}

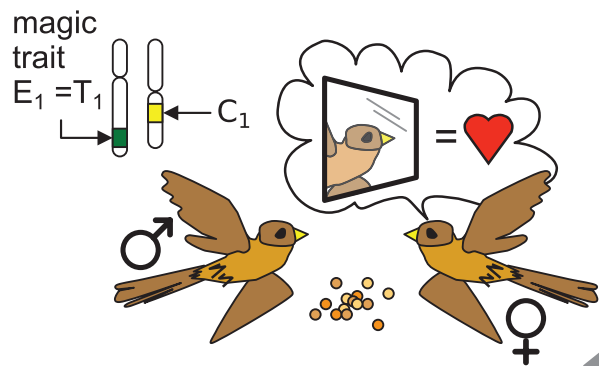

species 1 magic trait $\mathrm{E}_{2}=\mathrm{T}_{2}$

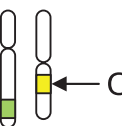

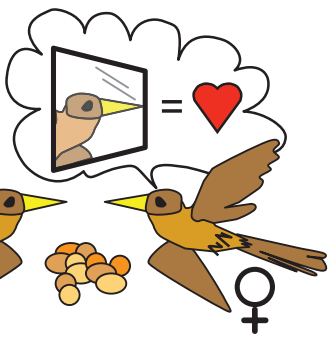

species 2

Figure 1: Assortative mating rules. $a$, Components of speciation with a preference/trait rule. The small-beaked population has red males and females that prefer red partners, whereas the large-beaked population has blue males and females that prefer blue partners. $\mathrm{P}$ is preference, $\mathrm{T}$ is a mating signal (color), $\mathrm{E}$ is an ecological trait (beak size), and $\mathrm{C}$ is choosiness. Differentiated alleles at these loci are denoted by subscripts. $b$, Components of speciation with a matching rule. Here females refer to their own phenotype (the mirrors) to determine the color that they prefer. $c$, Speciation with a matching rule and a magic trait (females prefer mates whose ecological trait resembles their own). Note that the choosiness locus, while shown monomorphic here, may often evolve because indirect selection against hybridization favors the replacement of weak-choosiness alleles by strong-choosiness alleles across both incipient species. However, this one-allele mechanism does not lead to population differentiation at this locus at the equilibrium state (i.e., after speciation has been completed).

behavior and, together with other model assumptions, determine the probability that a female will accept a male with trait value $T$. Indeed, the key feature of preference/trait models is that the loci controlling preferences are distinct from those controlling the mating traits $\mathrm{T}$ (figs. $1 a, 2 a$ ). In the simple discrete case shown in figure $1 a$, preference alleles $\mathrm{P}_{1}$ and $\mathrm{P}_{2}$ determine whether a female prefers red $\left(\mathrm{T}_{1}\right)$ or blue $\left(\mathrm{T}_{2}\right)$ males (see fig. $3 a$ ), and choosiness $\mathrm{C}$ is a measure of how much 


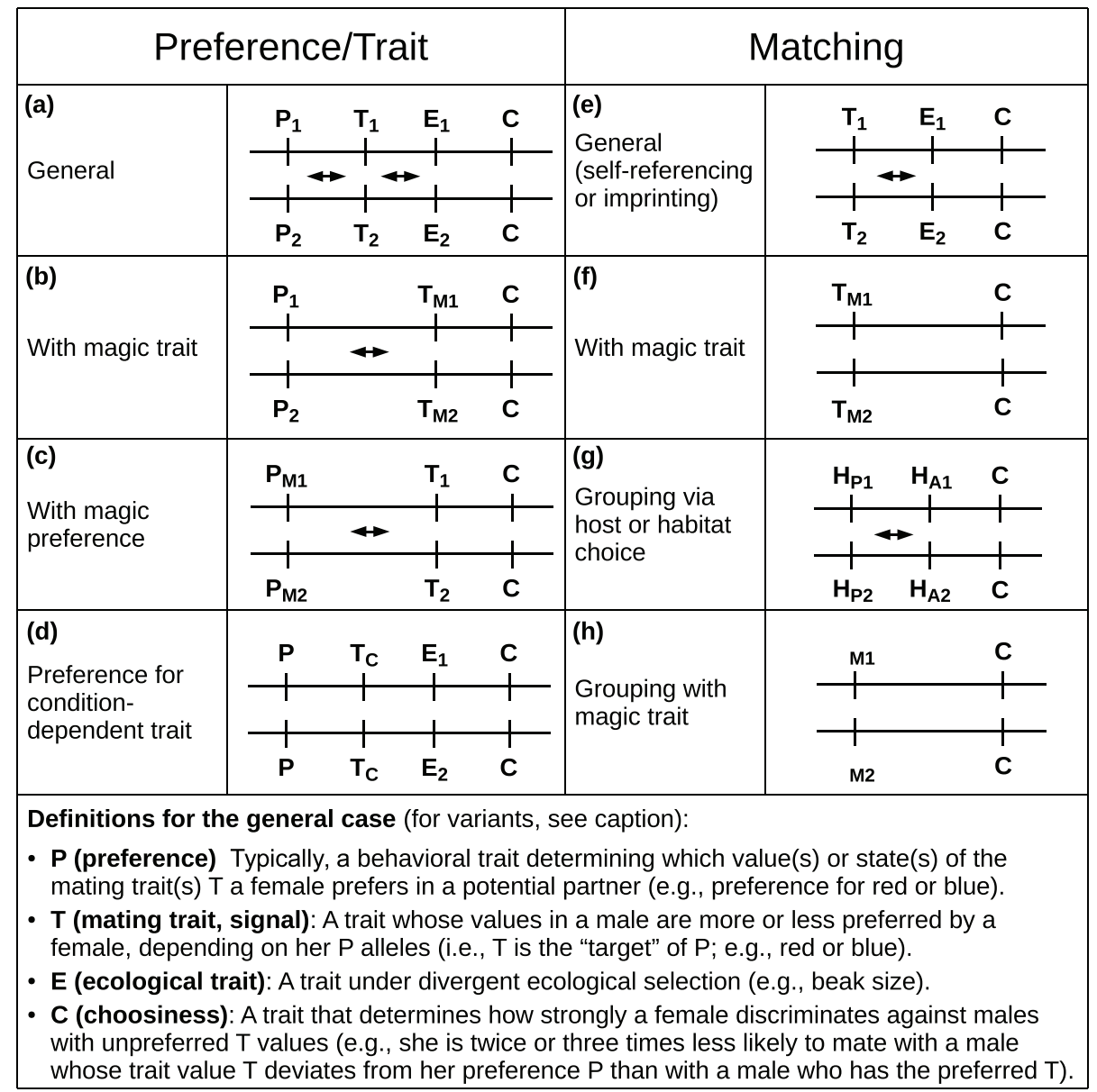

Figure 2: Schematic overview of genetic assumptions in simple speciation models with one locus per trait category. P alleles determine preference, $\mathrm{T}$ alleles a mating signal, $\mathrm{E}$ alleles an ecological trait, and $\mathrm{C}$ alleles choosiness. Arrows indicate linkage disequilibrium required for speciation. Alleles at polymorphic loci are denoted by subscripts. In $b, c$, and $f, \mathrm{~T}_{\mathrm{M}}$ and $\mathrm{P}_{\mathrm{M}}$ denote alleles for magic traits or magic preferences, respectively. In $d, \mathrm{~T}_{\mathrm{C}}$ indicates an allele for a condition-dependent trait. In $g, \mathrm{H}_{\mathrm{P}}$ alleles determine habitat or host preference (the grouping trait, which is analogous to $\mathrm{T}$ ), and $\mathrm{H}_{\mathrm{A}}$ alleles determine habitat adaptation (analogous to $\mathrm{E}$ ). In $h$, alleles $\mathrm{G}_{\mathrm{M}}$ determine a magic grouping trait (e.g., flowering time, if it is under divergent ecological selection). Note that choosiness alleles are usually not polymorphic at equilibrium, but many models assume that alleles for low choosiness can be invaded and replaced by alleles for higher choosiness (or vice versa).

she prefers one over the other (e.g., relative mating probabilities given an encounter). The continuous case is more complicated and requires the definition of a preference function, which ranks all possible phenotypes of potential mates. Such functions may differ widely in shape (see fig. $3 b, 3 c$ ), and in some cases, it may be difficult to clearly delineate preference versus choosiness (Edward 2014). In the case of a unimodal preference function (fig. $3 b$ ), preference is usually defined as its peak, that is, the most preferred male phenotype. Choosiness may then be defined as the strength of preference, that is, a feature of the shape of the preference function (e.g., the inverse of its width; Reinhold and Schielzeth 2015). Other authors define choosiness as the effort a female is prepared to invest in mate assessment (e.g., Jennions and Petrie 1997). When preferences are open-ended (e.g., favoring the largest or smallest trait value; fig. 3c), preference may be thought of as the sign of the slope of the preference function - or the direction in which the function opens - and choosiness as the magnitude of the slope (e.g., Cotton et al. 2006; Ratterman et al. 2014), but these characterizations are not universally used (e.g., Lande 1981) and are open to debate (reviewed in Edward 2014). While the distinction between preference and choosiness is conceptually useful (in that it separates the direction of preference from its strength), the underlying loci in the categories $\mathrm{P}$ and $\mathrm{C}$ cannot always be clearly separated from each other. For example, if a preference function is skewed (nonsymmetric around a maximum), mutations that affect its shape are likely to have pleiotropic effects on both preference (the mode of the function) and choosiness (its width). In any of these cases, however, zero choosiness is 
equivalent to random mating, which renders preferences in the category P neutral.

The last category of traits (E) comprises those under ecologically divergent selection, frequently called ecological traits. These traits may control locally adapted or ecologically specialized phenotypes, including performance in a certain habitat or on a certain food type (e.g., bill size in fig. $1 a$; for conditions of divergence, see Levene 1953; Geritz et al. 1998; Weissing et al. 2011; Bürger 2014). Since loci that are involved in intrinsic hybrid incompatibilities (Dobzhansky 1936; Muller 1942; Orr 1995; Gavrilets 1999; Bank et al. 2012a) can play an analogous role in speciation (e.g., in reinforcement models, when gene flow occurs after a period of allopatry; Servedio 2004), we also include them in this category.

\section{Matching Rules of Assortative Mating}

Unlike preference/trait rules, under which assortative mating depends on the maintenance of genetic polymorphism at a minimum of two distinct loci (P and T; fig. 2a), matching rules can generate assortative mating between incipient species by the divergence at $\mathrm{T}$ alone (figs. $1 b, 2 e$; table 1 ). In other words, there are no separate $P$ loci because a female's preference function is determined by (and usually centered around) her own trait value. Note, however, that the preference can still be more or less strong, so the concept of choosiness (loci C) applies as for a preference/trait rule. Also, ecological traits (loci E) play exactly the same role as above. Matching rules are assumed in a large number of theoretical models (e.g., Dieckmann and Doebeli 1999; Matessi et al. 2001; Rettelbach et al. 2013), and they can emerge from several behavioral or physiological mechanisms.

One behavioral mechanism of matching is self-referencing (or self-referent phenotype matching), wherein individuals inspect their own phenotype $\mathrm{T}$ and prefer mates with matching trait values (figs. $1 b, 2 e$ ). Self-referencing requires the use of an organism's own traits through self-inspection, potentially memorization, and comparison against the potential partner's respective traits (Hauber and Sherman 2001, 2003).

A similar mechanism is compatibility based on the same trait in both sexes, when males and females are constrained to mate with individuals expressing the same morphology (e.g., body size in some insects [Weissman et al. 2008] or shell chirality in snails, where only individuals expressing the same chirality are capable of mating with one another; Gittenberger 1988; Ueshima and Asami 2003). We note that there is an important difference between this type of mechanical compatibility, which depends on morphological similarity and leads to a matching rule, and mechanical fit, where males and females have different morphologies that must physically coordinate for successful coupling or stimulation, leading to a preference/trait rule (e.g., Brennan et al. 2007).
Another mechanism very similar to self-referencing is sexual imprinting on kin, since genetic relatives are also likely to share an individual's own phenotype (reviewed in Verzijden et al. 2012). There is, however, an important difference between imprinting and other matching mechanisms: parents or kin that are imprinted on may have different trait values than the imprinting individuals themselves; the individuals' acquired preference may therefore not match their own trait. In this sense, imprinting is technically only a proxy for matching. Nevertheless, imprinting on parents, for example, results in similar effects on trait divergence as does self-referencing, because both mechanisms operate by positive frequencydependent sexual selection based on the trait frequency (see below; although with paternal imprinting, the strength of sexual selection can be enhanced over both self-reference and maternal imprinting; Verzijden et al. 2005; Tramm and Servedio 2008). A preference established through imprinting may seem superficially similar to a genetic preference and thus be assumed to behave as in a preference/trait rule, but in the case of imprinting, the fact that the preference is developed from the trait places it under a matching rule instead. However, we caution that in some cases, preference may be for a phenotype that is shifted from the imprinted one (peak shift; e.g., Ten Cate et al. 2006). In this case, it is not known specifically how matching and preference/trait properties may combine, but theoretical models have shown that peak shift can potentially promote divergence (Gilman and Kozak 2015).

A matching mechanism that has several distinct properties from the ones described above is grouping, in which individuals sharing the same state of the mating trait $\mathrm{T}$ form aggregations wherein mating occurs, so that assortative mating based on $\mathrm{T}$ will result even if mating is random within these groups (O'Donald 1960; Maynard Smith 1966; Udovic 1980; Felsenstein 1981; Fry 2003; Otto et al. 2008; Norvaišas and Kisdi 2012). Grouping therefore does not require that females have any kind of phenotypically distinguishable preference at all, since matching is achieved via a single behavioral or physiological phenotype that determines group identity. Typical examples of grouping arise when individuals mate at different places (e.g., because of habitat or host choice) or times (e.g., because of flowering phenology [Hendry and Day 2005] or timing of migration [Rolshausen et al. 2009]). For instance, when organisms mate at or near their preferred habitats, a polymorphic locus for habitat preference $\left(\mathrm{H}_{\mathrm{P}}\right.$ in fig. $2 g$ ) plays the role of $\mathrm{T}$, whereas a locus for habitat adaptation $\left(\mathrm{H}_{\mathrm{A}}\right.$ in fig. $\left.2 g\right)$ plays the role of $\mathrm{E}$, and a locus modifying the strength of habitat preference would fall into category $\mathrm{C}$ (as would the evolution of increased philopatry).

Finally, matching can occur when mating preferences and traits are encoded by the same locus or suite of loci, that is, when the genes for preferences and traits are pleiotropic. This preference/trait pleiotropy (or genetic coupling; e.g., Butlin and Ritchie 1989) mechanism of matching entails two 


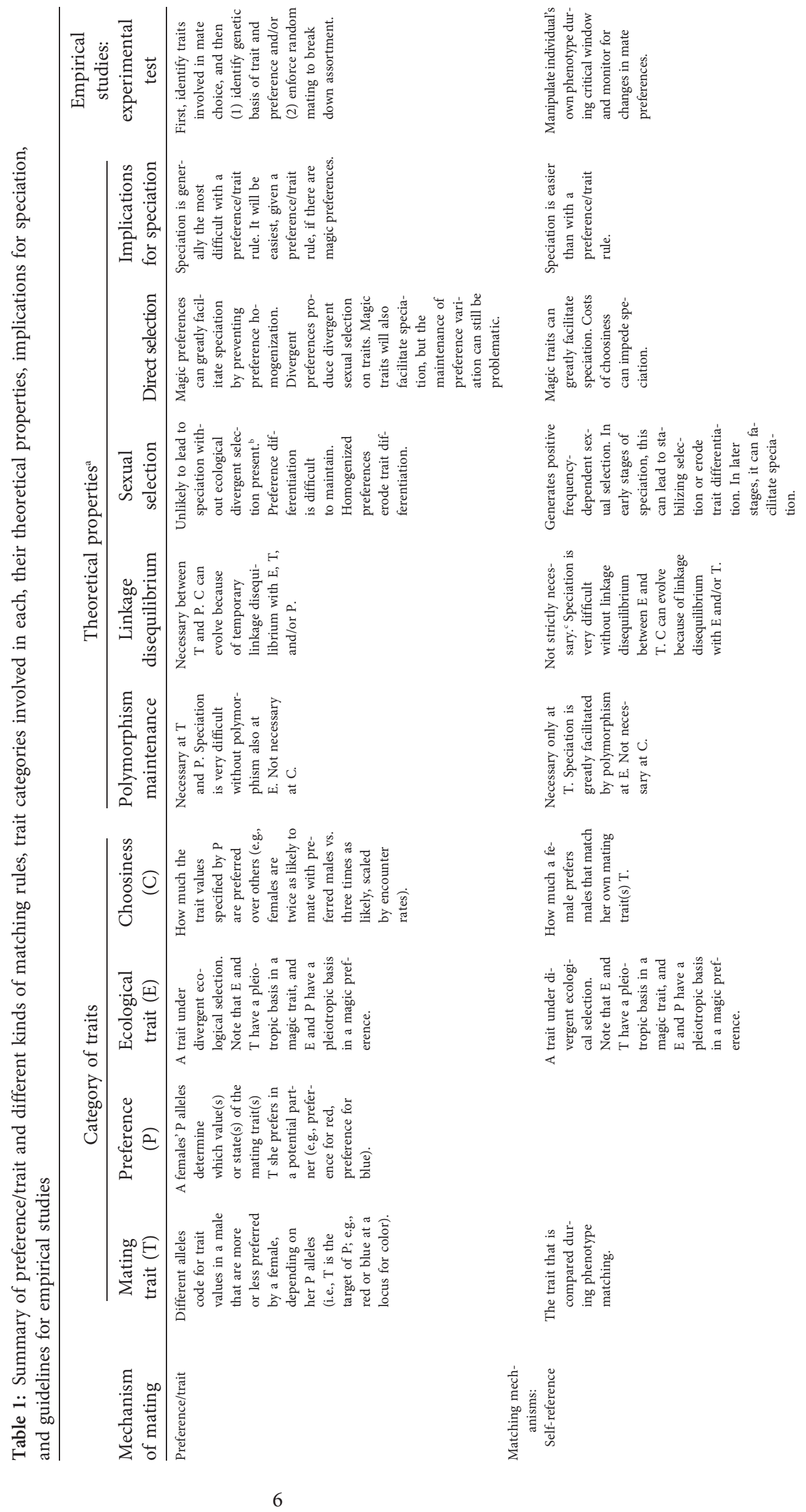



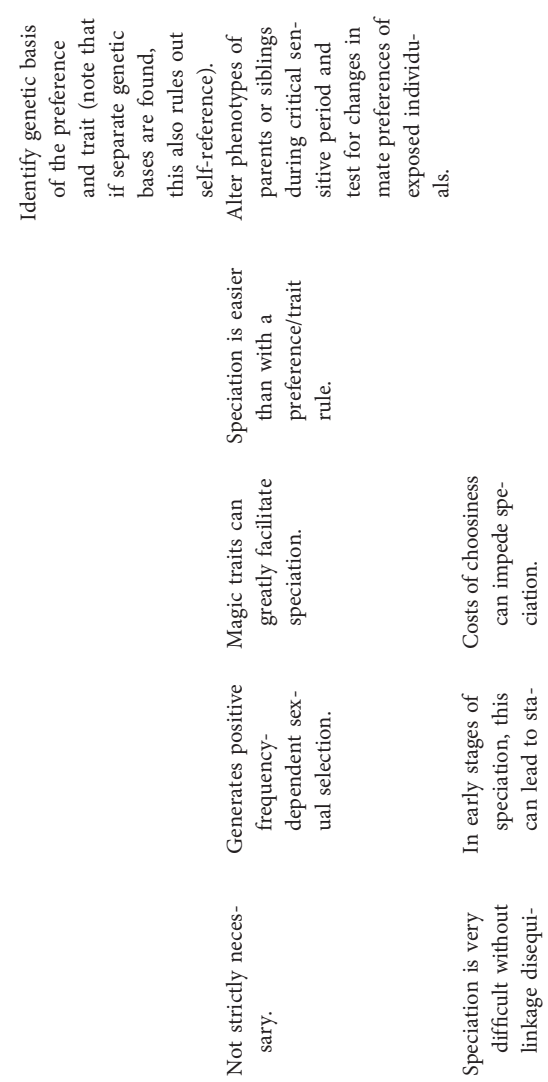

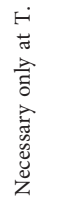
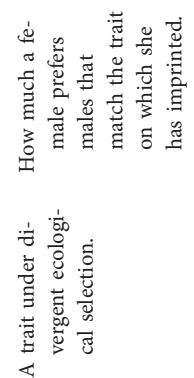
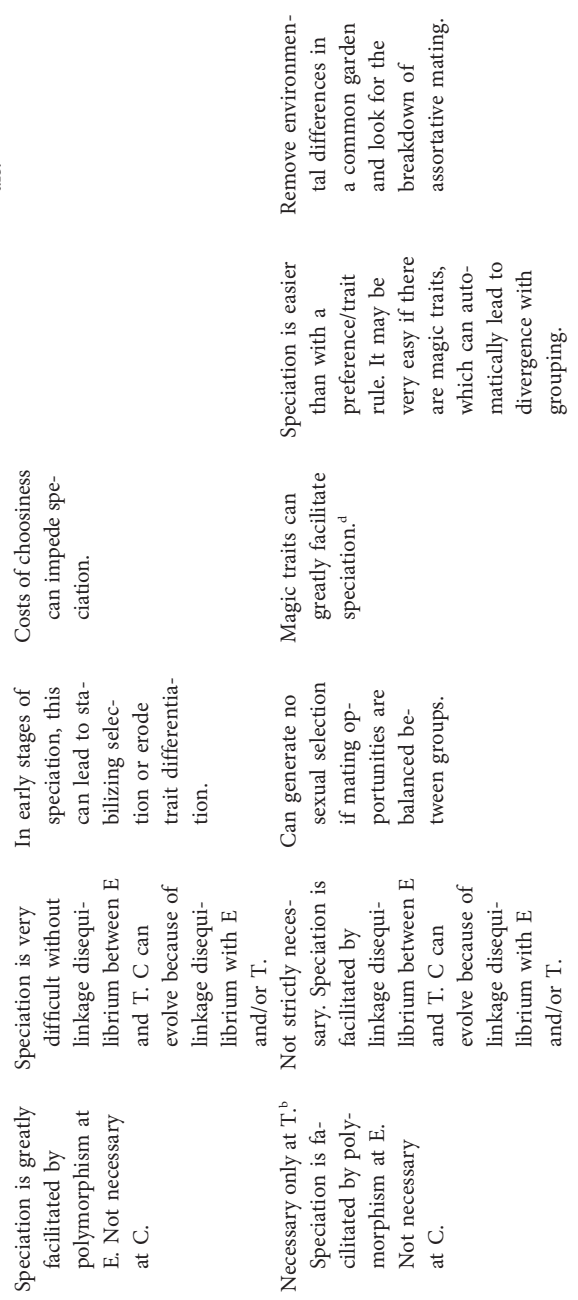

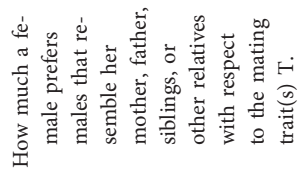

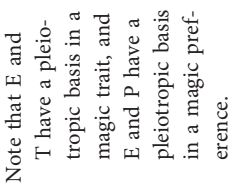

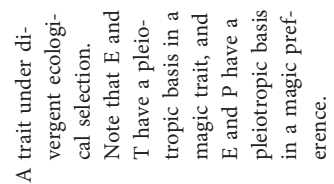

Mn
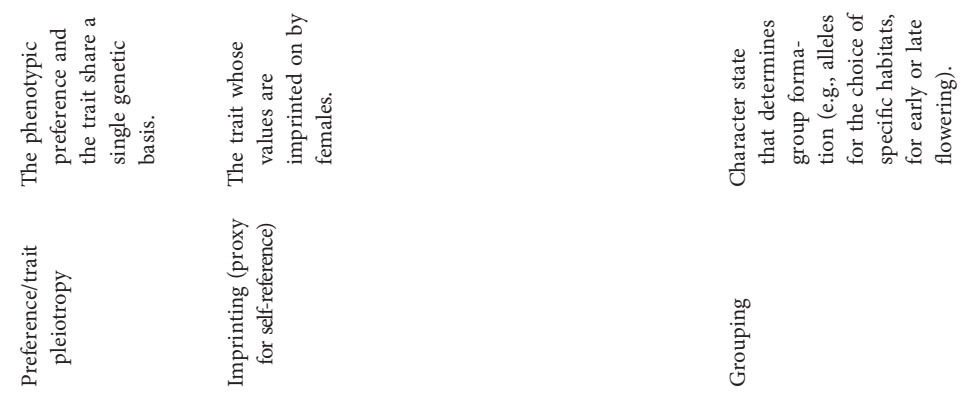

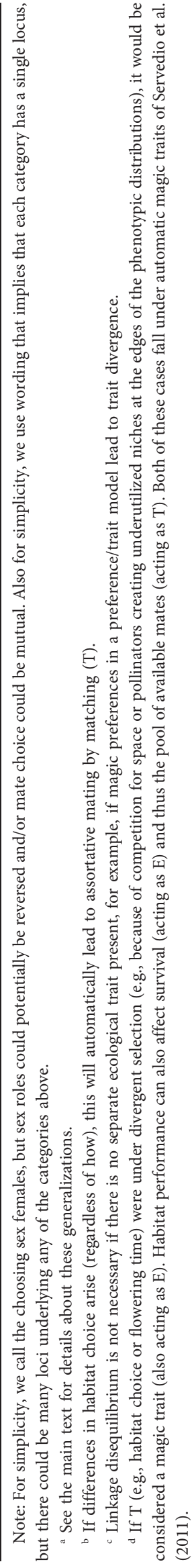




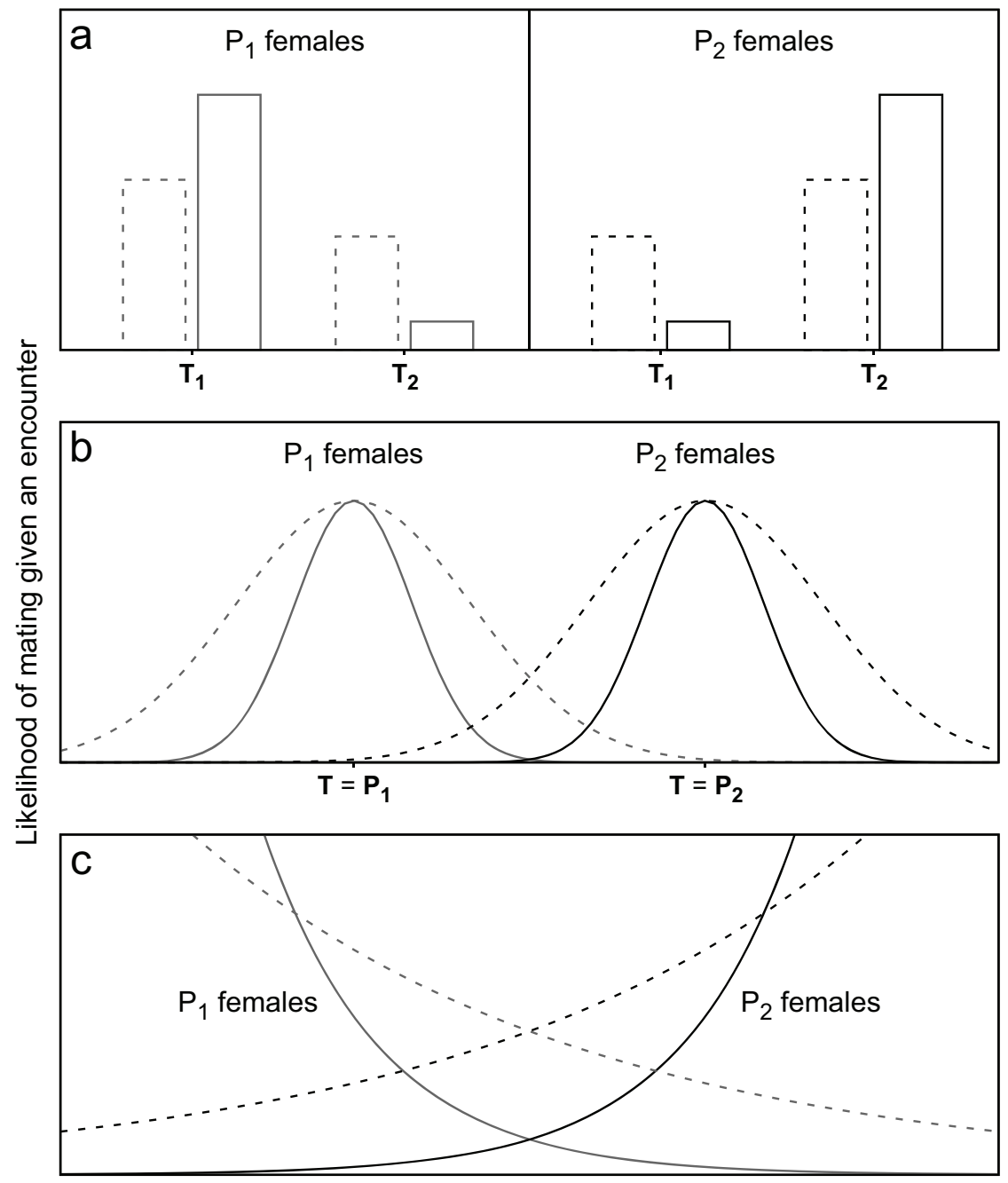

Male mating trait value, $\mathbf{T}$

Figure 3: Divergent female preference functions of different types. In all plots, preference functions corresponding to different female genotypes $\left(\mathrm{P}_{1}\right.$ and $\left.\mathrm{P}_{2}\right)$ are drawn in gray and black, respectively. Solid lines show high choosiness, and dashed lines show low choosiness. $a$, Simple discrete preference function for the case of two mating trait alleles $\left(\mathrm{T}_{1}\right.$ and $\left.\mathrm{T}_{2}\right) \cdot b$, Unimodal preference functions for a continuous male mating trait. The female preference alleles $\mathrm{P}_{1}$ and $\mathrm{P}_{2}$ correspond to the male trait values at the function maxima. $c$, Open-ended preference functions. The values of the preference alleles $\mathrm{P}_{1}$ and $\mathrm{P}_{2}$ might be given as positive or negative.

distinguishable phenotypes (one a property of the receiver and the other a physical or behavioral trait of the signaler), which are both determined by a single underlying genetic basis. Preference/trait pleiotropy is the focus of a growing body of empirical literature (see below).

We note that from a more abstract point of view, two of the above-mentioned matching mechanisms - self-referencing and mechanical compatibility - also behave in a pleiotropic manner. This can be demonstrated by a simple thought experiment: if a mutation were to occur that altered a female's trait phenotype at birth from $\mathrm{T}_{1}$ to $\mathrm{T}_{2}$, this would not only change her expressed trait but also cause her to have a preference for $\mathrm{T}_{2}$ males under self-referencing and a bias toward mating with $\mathrm{T}_{2}$ under a similarity-based mechanical compatibility mechanism. Pleiotropy can thus be thought of as a general property of several behavioral mechanisms of matching.

When preferences and traits are polygenic, it is possible that only some of the underlying genes are pleiotropic, whereas others are specific to either the preference or the trait. Such partial pleiotropy between preference and trait creates a gray area between preference/trait and matching models, showing that these two classes actually represent the end points of a continuum. The reason we nevertheless emphasize a simple dichotomy in this article is that it reflects the current state of the theoretical literature. Indeed, to the best of our knowledge, no model to date has analyzed the consequences of par- 
tial preference/trait pleiotropy on speciation with gene flow, even though there is empirical evidence for this phenomenon (see below).

\section{Effects of Mating Rules on Speciation: Expectations from Evolutionary Theory}

Although preference/trait and matching rules of assortative mating may seem superficially similar, there are well-established theoretical results that demonstrate important differences in the way they affect the evolution of reproductive isolation. These concern (1) the need for the maintenance of polymorphisms and (2) linkage disequilibrium, (3) the role of sexual selection, and (4) the effects of direct selection on the mating rule (summarized in table 1). Ultimately, these distinctions can lead to pronounced differences in the likelihood of speciation with gene flow, rendering speciation by a preference/trait rule particularly difficult.

Initial insight can be gained from the realization that both preference/trait and matching rules have components (described in more detail below) that correspond to the oneallele and two-allele models of Felsenstein (1981). Because we have seen these concepts cited in many different ways, some of which are in error, we return to Felsenstein (1981, p. 133), who defines them with the statement, "The critical distinction . . . is whether reproductive isolation is strengthened by substituting the same or different alleles in the two nascent species." In other words, two-allele mechanisms require the buildup of a genetic polymorphism (or divergence; we use the two terms synonymously) across incipient species, whereas one-allele mechanisms involve evolution but no polymorphism. This distinction can have important implications for the likelihood of speciation, which should be easier under a one-allele mechanism (Felsenstein 1981). Matching models are often associated with one-allele mechanisms and preference/trait models with two-allele mechanisms, but this view is overly simplistic. To take a reductionist approach, within our framework, preferences $(\mathrm{P})$, mating traits $(\mathrm{T})$ and ecological traits (E) act via a two-allele mechanism, whereas choosiness (C) evolves via a one-allele mechanism. The following two sections on the need for the maintenance of polymorphism and the role of linkage disequilibrium describe these issues in more depth.

\section{Speciation under a Preference/Trait Rule Requires Polymorphism or Divergence at a Minimum of One Extra Locus: Preference Polymorphism Is Hard to Maintain}

The root cause of the most critical differences between preference/trait and matching rules lies in the fact that in two otherwise equivalent biological scenarios, speciation under a preference/trait rule requires the evolution of polymor- phism (and thus an additional two-allele mechanism) at an extra category of loci (i.e., P; Felsenstein 1981; Servedio 2009; Smadja and Butlin 2011; cf. fig. 2a, 2e). Consider the very simplest case with two alleles per locus and high choosiness (such that females refuse to mate with a nonpreferred male). Under a matching rule, a polymorphism at a trait locus $\mathrm{T}$ alone would be enough to create two groups of reproductively isolated individuals, one with $T_{1}$ and one with $T_{2}$ (fig. $2 e$; note that this polymorphism could even be a polyphenism, with trait differences arising from learning or some other mechanism of nongenetic inheritance [e.g., Aoki 1989]). In contrast, under a preference/trait rule, polymorphisms at both categories $\mathrm{P}$ and $\mathrm{T}$ would be required, such that $P_{1}$ females, for example, mated with only $\mathrm{T}_{1}$ males and $\mathrm{P}_{2}$ females with only $\mathrm{T}_{2}$ males (fig. $2 a$; note that this remains true also when preferences are polygenic). Regardless of whether other categories of loci (e.g., E or C) are involved in a specific speciation scenario, preference/trait rules will always have this extra requirement for polymorphism, which is at the heart of the most critical differences between the two types of mating rules and renders speciation under a preference/trait rule intrinsically more difficult. This is especially true because the establishment and maintenance of preference polymorphism poses a particular evolutionary challenge (see below).

Unlike preferences and traits, choosiness typically evolves via a one-allele mechanism. Often models start from a condition of random mating (choosiness of zero), in which the mating rule is not effective at all. In many ecological-speciation models, an allele for increased choosiness reduces a female's risk of producing low-fitness offspring with intermediate phenotypes. In such cases, divergent ecological selection against hybrids exerts indirect selection for increased choosiness in both incipient species. This mechanism has been investigated in both matching models (e.g., Doebeli 1996; Dieckmann and Doebeli 1999; Matessi et al. 2001; Pennings et al. 2008) and preference/trait models (Doebeli 2005; Bank et al. 2012b; Servedio and Bürger 2014), although it occurs more rarely in the latter.

As we have seen, speciation under both mating rules combines mechanisms that are one-allele and two-allele in character. In some cases, the ease of evolving assortative mating may depend on the order in which the two mechanisms arise (Servedio 2009). For example, if strong choosiness via selfreferencing (a matching rule) is already in place, reproductive isolation can evolve via the buildup of polymorphism at $\mathrm{T}$, a two-allele mechanism. However, if the trait is ancestrally polymorphic, reproductive isolation can evolve if a single allele for increased choosiness (at C) spreads across both incipient species, constituting a one-allele mechanism (Matessi et al. 2001; Kopp and Hermisson 2008; Pennings et al. 2008; Servedio 2011).

Finally, in the vast majority of theoretical models and empirical scenarios, ecological traits (E) must be divergent across 
incipient species for speciation with gene flow to proceed, irrespective of the mating rule. While models can be constructed (Turner and Burrows 1995; Higashi et al. 1999; Takimoto et al. 2000; see also van Doorn and Weissing 2002) in which preference/trait divergence is generated or maintained in sympatry without underlying ecological divergence, speciation in these models is either very difficult or relies on unrealistic assumptions. Speciation by sexual selection alone is thus considered highly unlikely in the presence of gene flow (Arnegard and Kondrashov 2004; van Doorn et al. 2004; Weissing et al. 2011; Servedio and Bürger 2014; edge cases in Lande 1982; Payne and Krakauer 1997; but see M'Gonigle et al. 2012).

Speciation under a Preference/Trait Rule Requires Linkage Disequilibrium between More Sets of Loci: Reliance of Preference Evolution on Linkage Disequilibrium Makes Speciation Difficult

Under a preference/trait rule, assortative mating between individuals based on the mating trait $\mathrm{T}$ is realized only to the extent that alleles segregating at $\mathrm{T}$ and $\mathrm{P}$ loci are in linkage disequilibrium across the diverging subpopulations (e.g., $\mathrm{T}_{1}$ associated with $\mathrm{P}_{1}$, and $\mathrm{T}_{2}$ with $\mathrm{P}_{2}$; see fig. $2 a, 2 e$ ). While some level of linkage disequilibrium between these loci will arise as a consequence of nonrandom mating itself (Kirkpatrick 1982), strong linkage disequilibrium may be difficult to build up and maintain because it tends to be broken down by recombination if the loci are genetically unlinked (i.e., far apart or on separate chromosomes; see Felsenstein 1981).

Without strong linkage disequilibrium, however, the preference polymorphism itself becomes vulnerable to homogenization across populations. The reason is that - unless preferences are under direct divergent selection (see "The Roles of Sexual Selection in Speciation with Gene Flow Are Different under the Two Mating Rules") — divergence at P loci relies exclusively on indirect selection through the linkage disequilibrium with $\mathrm{T}$ (Lande 1981, 1982; Kirkpatrick 1982; note that divergence at $\mathrm{T}$ may itself depend on linkage disequilibrium with divergent E; fig. $2 a$; Servedio 2009; Smadja and Butlin 2011). Such linkage disequilibrium may be very weak unless preferences are very strong (i.e., choosiness is high), so in the early stages of sympatric speciation, indirect selection (transmitted via linkage disequilibrium) can be too weak to lead to preference divergence (van Doorn et al. 2004; Weissing et al. 2011). Preference divergence is likewise difficult to evolve or maintain in a situation of secondary contact (e.g., including during reinforcement; Servedio 2000), even when migration is restricted (Mendelson et al. 2014; Servedio and Bürger 2014), for the same reasons.

The obstacles to speciation that arise because of the requirement for the buildup and maintenance of strong linkage disequilibrium have sometimes led to the exaggerated impression that speciation with gene flow based on preference/trait rules cannot occur (e.g., since divergence at $\mathrm{P}$ and $\mathrm{T}$ both require two-allele mechanisms; Felsenstein 1981). However, many mathematical models have demonstrated that speciation is still possible in preference/trait systems, when preferences are subject to divergent ecological selection (magic preferences; see below) or even without direct selection on preferences (during sympatric speciation [Turner and Burrows 1995; Kondrashov and Kondrashov 1999], with spatial structure [Payne and Krakauer 1997]), particularly in the case of reinforcement (e.g., Liou and Price 1994; Servedio 2000; Kirkpatrick 2001; Doebeli 2005).

Linkage disequilibrium also plays an important role in the evolution of stronger choosiness (or any one-allele mechanism), which can occur via indirect selection because of linkage disequilibrium with underlying divergent traits (e.g., Dieckmann and Doebeli 1999; Matessi et al. 2001; Kirkpatrick and Nuismer 2004; Bürger and Schneider 2006; Otto et al. 2008; Pennings et al. 2008). This linkage disequilibrium, however, will not be present at evolutionary equilibrium, once the allele for stronger choosiness is fixed.

\section{The Roles of Sexual Selection in Speciation with Gene Flow Are Different under the Two Mating Rules}

The pattern of assortative mating (like mates with like) frequently generates sexual selection (differential mating success) on the underlying mating traits (but note that assortative mating and sexual selection are not the same and should not be confounded; Maan and Seehausen 2011; Servedio and Boughman 2017). The consequences of this sexual selection for speciation with gene flow are highly variable — sometimes promoting it and sometimes impeding it - and the details differ greatly between preference/trait and matching rules.

Self-referencing is perhaps the most common mechanism of assortative mating in theoretical studies, and the generation of sexual selection under this mechanism is well understood. If there is polygynous mating with no sexual dimorphism - one of the situations in which matching may be best envisioned-self-referencing will generate positive frequencydependent sexual selection (i.e., selection favoring the most common phenotype). This occurs because, unless assortment is perfect, males matching the most common female phenotype will have the highest reproductive success (e.g., Kirkpatrick and Nuismer 2004; Bürger et al. 2006; Otto et al. 2008; Pennings et al. 2008). This selection, which also occurs under imprinting (Verzijden et al. 2005; Yeh and Servedio 2015), can have different evolutionary consequences, depending on the geographic scenario and the degree of differentiation that is already established (reviewed in Servedio 2016).

On the one hand, positive frequency dependence generated by self-referencing can impede speciation during the early stages of sympatric speciation. In sympatry, initial trait dis- 
tributions are typically unimodal, causing sexual selection on the trait $\mathrm{T}$ to be effectively stabilizing and directly countering the divergent selection that is required for speciation to proceed (e.g., Matessi et al. 2001; Otto et al. 2008; Pennings et al. 2008; Ripa 2009; Labonne and Hendry 2010; it is this stabilizing sexual selection that is reduced by peak shift in the imprinting model of Gilman and Kozak 2015). In other cases, regardless of the geographic scenario, theoretical models show that positive frequency-dependent sexual selection can eliminate much or all of the trait variation on which assortative mating is based, also ultimately inhibiting divergence. This can occur both because stabilizing sexual selection can eliminate variation in a quantitative trait (Kirkpatrick and Nuismer 2004) and because, when trait distributions are initially skewed, positive frequency-dependent sexual selection can have a substantial directional component, which again reduces trait variation (Bürger and Schneider 2006; Bürger et al. 2006; Schneider and Bürger 2006; Otto et al. 2008; Pennings et al. 2008).

On the other hand, in the late stages of successful sympatric speciation, the distribution of the trait $\mathrm{T}$ in females will be bimodal, and the positive frequency-dependent sexual selection generated by self-referencing becomes largely divergent. This can drive further divergence and facilitate the completion of speciation (Otto et al. 2008; Pennings et al. 2008). Positive frequency-dependent sexual selection will similarly promote divergence when two populations are in secondary contact via the exchange of migrants (e.g., Servedio 2011; Rettelbach et al. 2013). Note, however, that when choosiness becomes very strong, positive frequency dependence will become increasingly weak because the mating success of rare males with rare females increases; this can cause the evolution of assortative mating to stall at an intermediate choosiness strength (Servedio 2011; Servedio and Bürger 2015; Cotto and Servedio 2017).

Unlike self-referencing and imprinting, grouping mechanisms of matching rules are typically assumed to generate little to no sexual selection (because mating is generally assumed to be random within groups). In fact, in the well-balanced scenarios of classical grouping models, sexual selection is completely absent (O’Donald 1960; Udovic 1980; Gavrilets 2004, 2006; Otto et al. 2008). In other cases, however, sexual selection may still arise, because asymmetries may cause some genotypes to have more mating opportunities across groups than others, and this can cause the loss of trait variation (Norvaišas and Kisdi 2012).

Under a preference/trait rule, female preferences are expected to generate substantial sexual selection on male mating traits. Theoretical models indicate that the effects of such selection may depend largely on the preference function in operation. As explained in the section on linkage disequilibrium above, the establishment and maintenance of preference divergence with unimodal (or absolute) preferences (fig. 3b) is difficult. When such preferences are not divergent enough, they can be a potent force of stabilizing sexual selection, preventing trait divergence and hence inhibiting speciation (Lande 1982; van Doorn et al. 2004; Weissing et al. 2011; Servedio and Bürger 2014). In contrast, when unimodal preferences are highly variable or divergent, or in cases with divergent open-ended (fig. $3 c$ ) and relative preferences, the amplification of ecologically based trait divergence can occur in sympatry (Kondrashov and Kondrashov 1999; Doebeli 2005), along a cline (Lande 1982; Payne and Krakauer 1997), or across two populations exchanging migrants (e.g., during reinforcement; Liou and Price 1994; Servedio 2000). We note that the majority of theoretical models with continuous traits assume unimodal preferences, so more work is needed with other preference functions.

Finally, we turn to a mechanism in which sexual selection can amplify ecologically based population differentiation without divergence of either preferences or traits. Specifically, if mating traits $(\mathrm{T})$ are condition dependent and act as reliable indicators of genetic or parental quality, then under divergent ecological selection, only locally adapted males will be able to develop an attractive ornament (Lorch et al. 2003). As long as spatial structure is maintained, females benefit from choosing a partner on the basis of the ornament because this allows them to produce locally adapted offspring (Proulx 2001; Reinhold 2004; van Doorn et al. 2009; Schindler et al. 2013; Veen and Otto 2015). While models of this process consider evolving traits and preferences, these do not diverge between species and therefore do not contribute to assortative mating via a preference/trait rule (fig. $2 d$ ). Instead, the evolution of condition-dependent mating traits acts to enhance already existing assortative mating resulting from the combination of divergent selection on the local adaptation trait (E) and mating within habitats. The ecological polymorphism here takes the role of a two-allele mechanism that serves as the basis for reproductive isolation, whereas sexual selection acts as a one-allele mechanism that strengthens the barrier to gene flow (e.g., via the evolution of increased choosiness).

\section{Magic Traits, Magic Preferences, and Costs: Different} Effects of Direct Selection under Different Mating Rules

Mate choice occurs in an ecological context that can exert selection pressures on mating rules, sexual signals, or choosiness in any number of ways (Endler 1992; Boughman 2002; Maan and Seehausen 2011; Safran et al. 2013). These interactions become important when ecological conditions differ between populations, as would be expected in a typical ecological-speciation scenario. Traits (T) that are subject to divergent ecological selection and that also contribute to nonrandom mating have been called magic traits (Gavrilets 2004; Servedio et al. 2011; see figs. $1 c, 2 b, 2 f$; table 1 ; for a critique of this terminology, see Smadja and Butlin 2011). The- 
oretical models have identified magic traits to be key facilitators of speciation because the pleiotropy of the underlying genes, which cannot be broken down by recombination, is much more effective than linkage disequilibrium in transmitting divergent ecological selection to the mating system (Dieckmann and Doebeli 1999; Kirkpatrick and Ravigné 2002; Gavrilets 2004).

The combination of a matching rule and a magic trait is particularly favorable for speciation (Smadja and Butlin 2011) because only a single trait needs to diverge in order to set the stage for the evolution of reproductive isolation and ecological specialization (i.e., no linkage disequilibrium is required; fig. $2 f$ ). Once an initial polymorphism at the magic trait locus has been established by divergent ecological selection, one-allele mechanisms - such as the evolution of increased choosiness - can evolve to further reduce gene flow (e.g., Dieckmann and Doebeli 1999; Matessi et al. 2001; Bolnick 2006; Pennings et al. 2008). The most favorable situation for divergence is when matching by a grouping mechanism occurs with a magic trait (fig. $2 h$; table 1 ; automatic magic traits of Servedio et al. 2011). For example, divergent ecological selection on habitat preferences (e.g., Diehl and Bush 1989; Fry 2003) or phenological traits (Dambroski and Feder 2007) leads instantly to assortative mating. Similarly, divergent selection on ecological traits automatically causes reproductive isolation (i.e., $\mathrm{E}$ is a magic trait) in the case of matching habitat choice, that is, when individuals choose habitats in which they have high fitness (Edelaar et al. 2008).

When nonrandom mating is based on a preference/trait mechanism, either the mating preference (magic preference) or the trait (magic trait) can be under direct divergent ecological selection (Servedio et al. 2011; fig. 2b, 2c). Theory predicts that both scenarios facilitate speciation but to different degrees. This difference results from the asymmetry between the strengths of selection acting on males and females under the assumptions of standard sexual selection models (van Doorn et al. 2004). Recall that the major difficulty of speciation via a preference/trait rule is that preferences are effectively homogenized by gene flow across populations (Servedio and Bürger 2014) because they are typically maintained only by weak indirect selection (Bulmer 1989; Kirkpatrick and Barton 1997); in contrast, if strong preferences were to sufficiently diversify, traits can readily follow (van Doorn and Weissing 2002; Stelkens et al. 2008; Weissing et al. 2011). The main conceptual challenge for sexual selection models of speciation with gene flow is therefore to explain how mating preferences can build up sufficient genetic variation to allow divergence (van Doorn et al. 2004). Divergent ecological selection on preferences can resolve this problem, suggesting that magic preferences provide an effective route to speciation (Maan and Seehausen 2012), for example, in the context of sensory drive (Boughman 2002). Magic traits at the $\mathrm{T}$ loci, on the other hand, facilitate the diversification of preferences only through indirect selection mechanisms, which will be unlikely to overcome the homogenizing force of gene flow (Servedio and Bürger 2014). In summary, direct divergent selection on the trait loci $\mathrm{T}$ involved in a matching rule can greatly facilitate speciation, as can direct divergent selection on the preference loci $\mathrm{P}$ in a preference/trait rule. In contrast, when the trait locus $\mathrm{T}$ is under divergent selection in a preference/trait rule, speciation with gene flow may still be somewhat difficult.

Finally, another important form of direct selection on components of mating rules are costs of choosiness, such as energetic search costs, exposure to predators, or a risk of remaining unmated (Bolnick and Fitzpatrick 2007; Otto et al. 2008; Kopp and Hermisson 2008). Several theoretical studies (e.g., Bolnick 2004; Gavrilets 2005; Bürger et al. 2006; Otto et al. 2008) have shown that costs of choosiness can effectively prevent speciation (e.g., by inducing sexual selection against rare females), even though this effect has been argued to be less prohibitory than initially thought (Kopp and Hermisson 2008). In contrast, costs of choosiness in a preference/trait model have recently been invoked as an important mechanism for the stabilization of species boundaries after secondary contact (M'Gonigle et al. 2012).

\section{Short Summary of Theoretical Expectations for Preference/Trait and Matching Rules}

The above discussion suggests that, in most cases, matching rules allow speciation with gene flow to occur more easily than do preference/trait rules. Speciation under a preference/ trait rule has two fundamental difficulties: it requires polymorphism at two categories of loci ( $\mathrm{P}$ and $\mathrm{T}$ ) and linkage disequilibrium between them. In particular, preference polymorphism is difficult to maintain if selection on preferences is indirect (i.e., with the exception of magic preferences); the homogenization of preferences can lead to the loss of trait divergence because of sexual selection.

\section{Mating Rules and Empirical Studies}

The theoretical work discussed above suggests that the difference between preference/trait and matching rules of assortative mating has far-reaching consequences for speciation in the presence of gene flow. Yet while there is empirical support for mechanisms underlying both types of mating rules, it remains unclear to date how common these different mechanisms are in nature (Scordato et al. 2014). We feel that this state of affairs arises, in large part, because (1) conclusive evidence for preference/trait rules requires knowledge of the underlying genetics, which is a challenging task even for model systems; (2) at the phenotypic level, the two types of mating rules may involve similar mechanisms and therefore be difficult to distinguish (e.g., imprinting on kin involves both 
signals and preferences, as in a preference/trait rule, but its effect is that of matching); and (3) both rules may be operating concurrently (something often neglected in theory). Below we discuss evidence of each mechanism that has been gathered to date and provide a guide to identifying further cases in natural systems (table 1).

\section{The Easy Cases: Grouping and Mechanical Compatibility}

Among the different assortative mating rules discussed in this article, grouping is probably the easiest to identify empirically (for potential difficulties in distinguishing the details of different kinds of grouping mechanisms, see Webster et al. 2012). Testing for grouping involves (1) demonstrating that organisms differentially gather at specific sites or times, with subsequent matings assortative by default, and (2) demonstrating the breakdown of assortative mating when those environmental factors are removed. For example, two host races of the ladybird beetle Henosepilachna diekei exhibit distinct host preferences and host performance but do not mate assortatively when brought into contact, providing strong evidence of grouping as the cause of assortative mating (Matsubayashi et al. 2011). Indeed, grouping may be a common form of matching by which assortative mating occurs in animals, especially insects. Many insects live in close association with plants, leading to tightly coevolved adaptations between specific or general assemblages of species. Plant-feeding insects often evolve strong host specialization and host preferences, such that individuals survive very poorly on foreign host plants and - when given the choice - do not remain on them for very long (Wood 1993; Berlocher and Feder 2002; Drès and Mallet 2002; Funk et al. 2002; Cocroft et al. 2008; Egan et al. 2008). The well-known example of the apple maggot fly Rhagoletis pomonella demonstrates how multiple grouping mechanisms can lead to assortative mating and eventual population divergence. Within the past 150 years, Rhagoletis pomonella has switched its host use from the fruits of native hawthorn trees to a number of domesticated varieties of apple. These host plant switches have led to several grouping features, including variation in the timing of diapause and eclosion associated with different host flowering times (Feder et al. 1993) and a grouping response to olfactory cues given off by the fruits of each host plant (Linn et al. 2003).

Similarly, the type of assortative mating rule should be rather easy to identify when it depends on mechanical (or biochemical) constraints. In particular, assortative mating based on mechanical compatibility corresponds to a matching rule when it depends on the presence of the same structure in both partners, as in chirality in snails (e.g., Gittenberger 1988), whereas it corresponds to a preference/trait rule when based on complementary sex-specific structures or receptors, for example, male and female genitalia (Eberhard 1985, 2009) or sperm and egg recognition proteins (Hirohashi et al. 2008).

\section{The Hard Cases: Behavioral Preference}

In contrast, the distinction between matching and preference/trait rules is most difficult when assortative mating involves mate choice mediated by a behavioral preference. In cases of assortative mating via mate choice, empirical studies usually do not give sufficient detail to distinguish between the two types of mating rules. In a review of nearly $1,500 \mathrm{em}$ pirical studies on sexual selection and speciation, 267 studies inferred reproductive isolation on the basis of some measure of divergent female mate choice or assortative mating (Scordato et al. 2014). Yet the observation that females prefer to mate with males that belong to their own morphotype, local population, or species cannot indicate whether this preference is genetically independent of the corresponding signaling trait(s). For example, red females might prefer to mate with red rather than blue males as a consequence of selfreferencing (a matching rule; the preference and trait are not independent) or because a red allele at a preference locus is in linkage disequilibrium with a red allele at an independent trait locus (a preference/trait rule). How then can these (and similar) scenarios be teased apart experimentally, and what do we currently know about them?

Evidence for Self-Referencing. The definitive test for selfreferencing is to experimentally manipulate the referent signal. This can be done either during ontogeny when the self-template is formed or during the behavior itself. If self-referencing is operating, then manipulating an individual's own cue should predictably alter the behavioral outcome (i.e., decreased kin association, reduced inbreeding, decreased assortative mating; Hauber and Sherman 2001, 2003). Hauber et al. (2000), for example, artificially dyed the plumage of fledgling brood parasitic Molothrus cowbirds (raised by heterospecifics) and demonstrated that subjects preferentially associated with conspecific adults whose own plumage had been similarly altered; in contrast, sham-manipulated subjects associated with sham-manipulated conspecific adults.

So far, empirical evidence suggests that self-referencing is not a particularly common mechanism of assortative mating (which is in stark contrast to its prevalence in theoretical models). Most studies examine self-referencing in the context of kin recognition and inbreeding avoidance (Keller and Ross 1998; Mateo and Johnston 2000; Hurst et al. 2001). In other examples, self-referencing promotes disassortativerather than assortative - mating. For example, mate choice on the basis of genetic or immunological compatibility favors potential mates that are dissimilar (Mays and Hill 2004). Obviously, self-referencing is not possible in sexually dimorphic species where the signal trait is expressed only in males.

Evidence for Imprinting. Another matching mechanism that involves a behavioral preference for a sexual signal is sexual 
imprinting on kin (Hebets and Sullivan-Beckers 2010). Testing for kin imprinting generally requires manipulating the social experience of focal organisms. For example, cross-fostering experiments and manipulation of parental traits have both been used to test whether mate preferences are affected by experience with kin. An important component of any such test is identifying whether there is a critical window in which most preferences are formed and/or whether preferences are shaped by ongoing experience. Failure to apply manipulations in the appropriate time window can lead to an underestimation of the importance of learning and imprinting and potentially an overestimation of the importance of selfreferencing (Hauber and Sherman 2003).

Imprinting is likely most common in taxa with parental care or where young are raised in groups. Kin imprinting is widespread in birds (Ten Cate and Vos 1999; Campbell and Hauber 2009), but there is also evidence of imprinting of mating preferences in other taxa, including mammals (Kendrick et al. 1998) and fish (Geritz et al. 1998; Hesse et al. 2012). For example, a cross-fostering experiment in cichlids revealed that females fostered by a heterospecific mother showed substantially more sexual response toward heterospecifics than individuals that had been raised by a conspecific mother (Verzijden and Ten Cate 2007), although cross-fostering did not affect the mating preferences of males (Verzijden et al. 2009).

Distinguishing Pleiotropy from True Preference/Trait Rules. If a system shows no evidence for either self-referencing or imprinting, it seems to be a prime candidate for a preference/ trait rule, but a matching rule is still possible if trait and preference have a pleiotropic genetic basis (even in sexually dimorphic species, where male trait and female preference might result from sex-limited expression of the same genes). Distinguishing between these cases ultimately requires pinpointing, directly or indirectly, the genetic basis of traits and preferences, which may be difficult. Thus, although preference/ trait rules are generally thought to be widespread (Andersson 1994; Andersson and Simmons 2006; Prum 2010), convincing evidence that rules out all other alternatives is hard to come by and hence rare. One exception is the European corn borer Ostrina nubilalis, where assortative mating is mediated by male preference for strain-specific blends of female pheromone. Since gene(s) responsible for pheromone production are autosomal, while those coding for attraction in males are sex linked (Roelofs et al. 1987; Löfstedt et al. 1989; Dopman et al. 2010), pleiotropy can be effectively ruled out. Additional indirect evidence for preference/trait rules comes from meta-analyses that assess the prevalence of genetic covariance between male signals and female preferences (Greenfield et al. 2014; Fowler-Finn and Rodríguez 2016). Many studies find weak to no covariance, suggesting that trait and preference are coded, at least in part, by different genes (even though the failure to find significant covariances has recently been argued to be due to a lack of statistical power; Sharma et al. 2016). Finally, another indirect test for preference/trait rules is to enforce random mating in assortatively mating populations for multiple generations (Servedio 2000); pleiotropy is unlikely if the association between trait and preference (and, consequently, assortative mating) breaks down. However, with both of these indirect approaches, high or persistent covariance does not allow pleiotropy and tight linkage to be distinguished.

Empirical support for preference/trait pleiotropy has been found in a few specific cases, but the evidence is rarely complete. In two studies of Heliconius butterflies, a single quantitative trait locus (QTL) has been implicated in both the expression of species-specific wing bar color (a mating trait) and male preference for those colors. Kronforst et al. (2006) found a single QTL contributing to both forewing coloration and male color preference in Heliconius pachinus and Heliconius cydno, and Merrill et al. (2011) found a single QTL (not the same as Kronforst et al. 2006) contributing to both forewing coloration and male color preference in Heliconius melpomene and H. cydno. In the Hawaiian cricket genus Laupala, the species-specific pulse rate of male courtship song and female preferences for conspecific pulse rates were mapped to common QTLs (Shaw and Lesnick 2009; Wiley and Shaw 2010; Wiley et al. 2012). In Drosophila mauritiana and Drosophila simulans, a single genomic region was implicated in female preference for conspecific males and male attractiveness to conspecific females (McNiven and Moehring 2013). Importantly, however, not only do these examples also find additional loci that are exclusive to preference or trait, but also - as pointed out by the authors in each case - the results might reflect tight physical linkage between different loci that map to the same QTL, so a preference/trait rule cannot be ruled out. A more conclusive potential example of preference/ trait pleiotropy comes from Drosophila melanogaster, in which a single gene, desat 1, appears to affect both pheromone perception and synthesis (Marcillac et al. 2005; Houot et al. 2010; Bousquet et al. 2012). These studies on desat1 are not examples of assortative mating in a speciation context. However, a different desaturase gene has been implicated in sexual isolation between D. melanogaster races (Fang et al. 2002; Coyne and Elwyn 2006), suggesting that desat 1 may also ultimately have implications for speciation.

Multiple Mechanisms. We note that many of the mechanisms described above can interact either simultaneously or sequentially (e.g., Wood 1980), perhaps increasing the likelihood of speciation. An example of a variety of mechanisms at play occurs in the Enchenopa binotata complex of treehoppers (Hemiptera: Membracidae). First, there are at least three forms of ecologically based grouping (Wood 1993; Cocroft et al. 2008). Each species in this clade specializes on a differ- 
ent host plant species and survives poorly on the hosts of other species. They also have strong behavioral preferences for their own host plant. Finally, treehoppers on host plants with different phenologies acquire differences in the timing of their mating seasons because of plasticity in the timing of embryo development. In addition to these grouping mechanisms, preference/trait mechanisms are also at play via systems of plant-borne vibrational signaling (Cocroft et al. 2008). Pair formation involves male-female signal exchanges (duets), with strong female preferences for certain male signal features (Cocroft et al. 2008). These signals and mate preferences likely represent a preference/trait mechanism because within-species genetic correlations between signals and preferred signal values are weak or absent (Fowler-Finn et al. 2015), in spite of pronounced signal-preference coevolution between species (Rodríguez et al. 2006; Cocroft et al. 2008). Thus, a multiplicity of mechanisms plays a role in the process of divergence in this species complex, perhaps with different mechanisms making varying contributions at different stages. The evolution of competing or complementary mating rules has only recently been considered in theoretical studies (e.g., Gavrilets et al. 2007; Thibert-Plante and Gavrilets 2013).

\section{Empirical Summary}

Empiricists studying mating behavior in the context of speciation with gene flow generally do not use the same classification schemes as theoreticians. While there are empirical examples of all types of mating rules discussed above, little is known about their relative prevalence in natural populations. The various types of matching appear to be the easiest to demonstrate empirically and might be common in at least some taxa (e.g., imprinting in birds and grouping in phytophagous insects). Preference/trait rules are generally thought to be widespread, but firmly establishing such a rule requires extensive work in both the field and the laboratory. Such research is ongoing and will continue to add important contributions to our understanding of the behavior and genetics of mate selection. Furthermore, evidence from well-studied systems indicates that mating behavior may often depend on the interaction of several distinct mechanisms, which suggests new extensions to theoretical work (e.g., which combinations or sequences of mating rules are most likely to lead to speciation).

\section{Conclusions: Theoretical and Empirical Perspectives on Speciation with Gene Flow}

Theoretical and empirical evolutionary biologists studying speciation do so from different (and complementary) perspectives, and we believe that this accounts, at least in part, for their distinct approaches toward categorizing assortative mating. Empirical studies typically can access only a snap- shot of a potentially ongoing speciation process. The focus is then on elucidating which specific mechanisms are presently acting in the system (e.g., Is there assortative mating? If yes, which traits is it based on? What is the genetic basis of these traits? Which trait values are favored by natural or sexual selection?) and on describing the current status of speciation (the degree of reproductive isolation and phenotypic or genetic differentiation). In contrast, theoretical models focus on how certain assortative mating mechanisms influence the long-term dynamics and outcome (i.e., equilibrium state) of the speciation process.

In these efforts, the two approaches face very different challenges. For empiricists, certain mechanisms — such as whether preferences and traits share a common genetic basis - may simply be hard to study in a given system. In contrast, a theoretician always has perfect knowledge of the specific mechanisms implemented in a model (e.g., the genotype-phenotype map). The difficulty is rather to derive a tractable model that replaces many biological details (e.g., of courtship behavior) with suitable idealizations and yet still captures the essence of the biological problem. Alternative models or sets of assumptions can then be seen as different hypothetical scenarios whose analysis can help to distill the key factors influencing the process of interest.

Here, we have shown that a large body of theoretical literature has identified the distinction between preference/trait and matching rules of assortative mating as a key determinant of the likelihood that speciation will succeed in the presence of gene flow. Because this is a question about long-term equilibrium states (and thus falls into the domain of theoretical approaches), we argue that speciation research will benefit if this classification scheme is also applied by empiricists. In particular, we urge empiricists to consider whether, in their study system, female preference (or an analogous [e.g., mechanical] trait) has an independent genetic basis from the male signaling trait. A start to this determination could be to perform QTL studies or enforce random mating in a laboratory population, both of which could establish whether preferences and traits are independently controlled.

Ultimately, organizing empirical evidence from across a variety of specific mechanisms into the categories of preference/trait and matching rules can give us important insights into how common speciation with gene flow may be in particular taxa and what theoretical obstacles it may most often face. These goals are most likely to be accomplished by means of broad comparative studies that assess the prevalence of preference/trait versus matching rules in (1) partially divergent populations that are thought to be in the process of speciation with gene flow, (2) fully isolated species pairs that are thought to have diverged in the presence of gene flow, and (3) species that have not recently speciated or that are thought to have formed in allopatry. In particular, categories 1 and 2 should not be grouped together, since except in unusual 
circumstances it cannot be inferred that the presence of some current assortative mating implies that speciation will ultimately proceed. Category 3 can indicate the prevalence of different mate choice mechanisms in general, without the restriction that some divergence between subpopulations has already been accomplished.

What might we find from such studies? Theoretical results would predict that even if preference/trait mechanisms were generally more common, matching mechanisms should be overrepresented among the taxa that have successfully speciated despite contact. The degree of such overrepresentation, if it exists, would be of great interest. Additionally, if matching turns out to be more common in general than currently appreciated, the potential for speciation with gene flow could be greater than previously thought. Attention should also be paid to evidence for magic traits and preferences, which will facilitate speciation under both mating rules. The frequency of occurrence of different mating rules and of magic traits will undoubtedly vary across taxa, which should give speciation researchers a better appreciation for which taxa would be expected to more commonly speciate despite gene flow and hence help to identify promising candidates for future studies of (incipient) speciation.

If, in contrast, it turns out that speciation with gene flow frequently proceeds in taxa with preference/trait rules, this would highlight the need for further refinement of theoretical models because theoreticians would then need to explain how the difficulties described above can be overcome. For example, such a finding might trigger the development of more complex and realistic models that incorporate multiple interacting mate choice mechanisms and multifarious ecological selection pressures. Ultimately, both theoretical and empiri$\mathrm{cal}$ approaches need to become more integrated in order to increase our understanding of the origin of biodiversity without geographic barriers.

\section{Acknowledgments}

This work was facilitated by the National Evolutionary Synthesis Center (NESCent) through the National Science Foundation (NSF) EF-0905606 award. We thank the NESCent staff for their assistance and the other members of our working groups on "An integrative evolutionary approach to examine sexual selection as a mechanism of speciation" and "Toward a unified evolutionary theory of decision making in animals" for helpful discussions. M.R.S. was funded by the NSF grant DEB 1255777. R.L.R. was funded by NSF grant IOS- 1120790 to R.L.R. and K. D. Fowler-Finn. R.J.S. was funded by NSF grant DEB-CAREER 1149942. M.E.H. was funded by NSF grant IOS-1456524. C.N.B. was funded by NSF grant IOS-1456612. D.M.Z. was funded by a NESCent Graduate Student Fellowship. G.S.v.D. was supported by the European Research Council (starting grant 309555) and the
Netherlands Organisation for Scientific Research (Vidi grant 864.11.012). We thank Yannis Michalakis, Roger Butlin, Trevor Price, and one anonymous reviewer for helpful comments on the manuscript.

\section{Literature Cited}

Aguilée, R., A. Lambert, and D. Claessen. 2011. Ecological speciation in dynamic landscapes. Journal of Evolutionary Biology 24:2663-2677.

Andersson, M. 1994. Sexual selection. Princeton University Press, Princeton, NJ.

Andersson, M., and L. W. Simmons. 2006. Sexual selection and mate choice. Trends in Ecology and Evolution 21:296-302.

Aoki, K. 1989. A sexual-selection model for the evolution of imitative learning of song in polygynous birds. American Naturalist 134: 599-612.

Arnegard, M. E., and A. S. Kondrashov. 2004. Sympatric speciation by sexual selection alone is unlikely. Evolution 58:222-237.

Bank, C., R. Bürger, and J. Hermisson. 2012a. The limits to parapatric speciation: Dobzhansky-Muller incompatibilities in a continentisland model. Genetics 191:845-863.

Bank, C., J. Hermisson, and M. Kirkpatrick. 2012b. Can reinforcement complete speciation? Evolution 66:229-239.

Berlocher, S. H., and J. L. Feder. 2002. Sympatric speciation in phytophagous insects: moving beyond controversy? Annual Review of Entomology 47:773-815.

Bolnick, D. I. 2004. Waiting for sympatric speciation. Evolution 58:895899.

- 2006. Multi-species outcomes in a common model of sympatric speciation. Journal of Theoretical Biology 241:734-744.

Bolnick, D. I., and B. M. Fitzpatrick. 2007. Sympatric speciation: models and empirical evidence. Annual Review of Ecology, Evolution, and Systematics 38:459-487.

Boughman, J. W. 2002. How sensory drive can promote speciation. Trends in Ecology and Evolution 17:571-577.

Bousquet, F., T. Nojima, B. Houot, I. Chauvel, S. Chaudy, S. Dupas, D. Yamamoto, and J.-F. Ferveur. 2012. Expression of a desaturase gene, desat1, in neural and nonneural tissues separately affects perception and emission of sex pheromones in Drosophila. Proceedings of the National Academy of Sciences of the USA 109:249-254.

Brennan, P. L., R. O. Prum, K. G. McCracken, M. D. Sorenson, R. E. Wilson, and T. R. Birkhead. 2007. Coevolution of male and female genital morphology in waterfowl. PLoS ONE 2:e418.

Bulmer, M. 1989. Structural instability of models of sexual selection. Theoretical Population Biology 35:195-206.

Bürger, R. 2014. A survey of migration-selection models in population genetics. Discrete and Continuous Dynamical Systems B 19:883-959.

Bürger, R., and K. Schneider. 2006. Intraspecific competitive divergence and convergence under assortative mating. American Naturalist 167: 190-205.

Bürger, R., K. Schneider, and M. Willensdorfer. 2006. The conditions for speciation through intraspecific competition. Evolution 60:21852206.

Butlin, R., and M. Ritchie. 1989. Genetic coupling in mate recognition systems: what is the evidence? Biological Journal of the Linnean Society $37: 237-246$.

Campbell, D. L., and M. E. Hauber. 2009. Cross-fostering diminishes song discrimination in zebra finches (Taeniopygia guttata). Animal Cognition 12:481-490. 
Cocroft, R. B., R. L. Rodríguez, and R. E. Hunt. 2008. Host shifts, the evolution of communication, and speciation in the Enchenopa binotata species complex of treehoppers. Pages 88-100 in K. Tilmon, ed. Specialization, speciation, and radiation: the evolutionary biology of herbivorous insects. University of California Press, Berkeley.

Cotto, O., and M. R. Servedio. 2017. The roles of sexual and viability selection in the evolution of incomplete reproductive isolation: from allopatry to sympatry. American Naturalist 190:680-693.

Cotton, S., J. Small, and A. Pomiankowski. 2006. Sexual selection and condition-dependent mate preferences. Current Biology 16:R755-R765.

Coyne, J. A., and S. Elwyn. 2006. Does the desaturase-2 locus in Drosophila melanogaster cause adaptation and sexual isolation? Evolution 60:279-291.

Coyne, J. A., and H. A. Orr. 2004. Speciation. Sinauer, Sunderland, MA.

Dambroski, H., and J. Feder. 2007. Host plant and latitude-related diapause variation in Rhagoletis pomonella: a test for multifaceted life history adaptation on different stages of diapause development. Journal of Evolutionary Biology 20:2101-2112.

Dieckmann, U., and M. Doebeli. 1999. On the origin of species by sympatric speciation. Nature 400:354-357.

Dieckmann, U., M. Doebeli, J. A. J. Metz, and D. Tautz, eds. 2004. Adaptive speciation. Cambridge University Press, Cambridge.

Diehl, S. R., and G. L. Bush. 1989. The role of habitat preference in adaptation and speciation. Pages 345-365 in D. Otte and J. Endler, eds. Speciation and its consequences. Sinauer, Sunderland, MA.

Dobzhansky, T. 1936. Studies on hybrid sterility. II. Localization of sterility factors in Drosophila pseudoobscura hybrids. Genetics 21:113135.

Doebeli, M. 1996. A quantitative genetic competition model for sympatric speciation. Journal of Evolutionary Biology 9:893-909.

2005. Adaptive speciation when assortative mating is based on female preference for male marker traits. Journal of Evolutionary Biology 18:1587-1600.

Dopman, E. B., P. S. Robbins, and A. Seaman. 2010. Components of reproductive isolation between North American pheromone strains of the European corn borer. Evolution 64:881-902.

Drès, M., and J. Mallet. 2002. Host races in plant-feeding insects and their importance in sympatric speciation. Philosophical Transactions of the Royal Society B 357:471-492.

Eberhard, W. G. 1985. Sexual selection and animal genitalia. Harvard University Press, Cambridge, MA.

- 2009. Postcopulatory sexual selection: Darwin's omission and its consequences. Proceedings of the National Academy of Sciences of the USA 106:10025-10032.

Edelaar, P., A. M. Siepielski, and J. Clobert. 2008. Matching habitat choice causes directed gene flow: a neglected dimension in evolution and ecology. Evolution 62:2462-2472.

Edward, D. A. 2014. The description of mate choice. Behavioral Ecology 26:301-310.

Egan, S. P., P. Nosil, and D. J. Funk. 2008. Selection and genomic differentiation during ecological speciation: isolating the contributions of host association via a comparative genome scan of Neochlamisus bebbianae leaf beetles. Evolution 62:1162-1181.

Endler, J. A. 1992. Signals, signal conditions, and the direction of evolution. American Naturalist 139(suppl.):S125-S153.

Fang, S., A. Takahashi, and C.-I. Wu. 2002. A mutation in the promoter of desaturase 2 is correlated with sexual isolation between Drosophila behavioral races. Genetics 162:781-784.

Feder, J. L., T. A. Hunt, and L. Bush. 1993. The effects of climate, host plant phenology and host fidelity on the genetics of apple and haw- thorn infesting races of Rhagoletis pomonella. Entomologia Experimentalis et Applicata 69:117-135.

Felsenstein, J. 1981. Skepticism towards Santa Rosalia, or why are there so few kinds of animals. Evolution 35:124-138.

Fisher, R. A. 1930. The genetical theory of natural selection: a complete variorum edition. Oxford University Press, Oxford.

Fowler-Finn, K. D., J. T. Kilmer, A. C. Hallett, and R. L. Rodríguez. 2015. Variation in signal-preference genetic correlations in Enchenopa treehoppers (Hemiptera: Membracidae). Ecology and Evolution 5:27742786.

Fowler-Finn, K. D., and R. L. Rodríguez. 2016. The causes of variation in the presence of genetic covariance between sexual traits and preferences. Biological Reviews 91:498-510.

Fry, J. D. 2003. Multilocus models of sympatric speciation: Bush versus Rice versus Felsenstein. Evolution 57:1735-1746.

Funk, D. J., K. E. Filchak, and J. L. Feder. 2002. Herbivorous insects: model systems for the comparative study of speciation ecology. Pages 251-267 in W. J. Etges and M. A. F. Noor, eds. Genetics of mate choice: from sexual selection to sexual isolation. Springer, Berlin.

Futuyma, D. J. 1998. Evolutionary biology. Sinauer, Sunderland, MA.

Gavrilets, S. 1999. A dynamical theory of speciation on holey adaptive landscapes. American Naturalist 154:1-22.

- 2004. Fitness landscapes and the origin of species. Princeton University Press, Princeton, NJ.

- 2005. "Adaptive speciation"-it is not that easy: a reply to Doebeli et al. Evolution 59:696-699.

- 2006. The Maynard Smith model of sympatric speciation. Journal of Theoretical Biology 239:172-182.

Gavrilets, S., A. Vose, M. Barluenga, W. Salzburger, and A. Meyer. 2007. Case studies and mathematical models of ecological speciation. 1. Cichlids in a crater lake. Molecular Ecology 16:2893-2909.

Geritz, S. A. H., E. Kisdi, G. Meszéna, and J. A. J. Metz. 1998. Evolutionary singular strategies and the adaptive growth and branching of the evolutionary tree. Evolutionary Ecology 12:35-57.

Gilman, R. T., and G. M. Kozak. 2015. Learning to speciate: the biased learning of mate preferences promotes adaptive radiation. Evolution 69:3004-3012.

Gittenberger, E. 1988. Sympatric speciation in snails: a largely neglected model. Evolution 42:826-828.

Greenfield, M. D., S. Alem, D. Limousin, and N. W. Bailey. 2014. The dilemma of Fisherian sexual selection: mate choice for indirect benefits despite rarity and overall weakness of trait-preference genetic correlation. Evolution 68:3524-3536.

Hauber, M. E., and P. W. Sherman. 2001. Self-referent phenotype matching: theoretical considerations and empirical evidence. Trends in Neurosciences 24:609-616.

- 2003. Designing and interpreting experimental tests of selfreferent phenotype matching. Animal Cognition 6:69-71.

Hauber, M. E., P. W. Sherman, and D. Paprika. 2000. Self-referent phenotype matching in a brood parasite: the armpit effect in brownheaded cowbirds (Molothrus ater). Animal Cognition 3:113-117.

Hebets, E., and L. Sullivan-Beckers. 2010. Mate choice and learning. Pages 389-393 in M. Bekoff, ed. Encyclopedia of animal behavior. Vol. 2. Academic Press, Cambridge, MA.

Hendry, A. P., and T. Day. 2005. Population structure attributable to reproductive time: isolation by time and adaptation by time. Molecular Ecology 14:901-916.

Hesse, S., T. C. Bakker, S. A. Baldauf, and T. Thünken. 2012. Kin recognition by phenotype matching is family- rather than self-referential in juvenile cichlid fish. Animal Behaviour 84:451-457. 
Hey, J. 2006. Recent advances in assessing gene flow between diverging populations and species. Current Opinion in Genetics and Development 16:592-596.

Higashi, M., G. Takimoto, and N. Yamamura. 1999. Sympatric speciation by sexual selection. Nature 402:523-526.

Hirohashi, N., N. Kamei, H. Kubo, H. Sawada, M. Matsumoto, and M. Hoshi. 2008. Egg and sperm recognition systems during fertilization. Development, Growth and Differentiation 50:S221-S238.

Houot, B., F. Bousquet, and J.-F. Ferveur. 2010. The consequences of regulation of desat1 expression for pheromone emission and detection in Drosophila melanogaster. Genetics 185:1297-1309.

Hurst, J. L., C. E. Payne, C. M. Nevison, A. D. Marie, R. E. Humphries, D. H. Robertson, A. Cavaggioni, and R. J. Beynon. 2001. Individual recognition in mice mediated by major urinary proteins. Nature 414 : 631-634.

Iwasa, Y., and A. Pomiankowski. 1999. Good parent and good genes models of handicap evolution. Journal of Theoretical Biology 200: 97-109.

Jennions, M. D., and M. Petrie. 1997. Variation in mate choice and mating preferences: a review of causes and consequences. Biological Reviews 72:283-327.

Jiang, Y., D. I. Bolnick, and M. Kirkpatrick. 2013. Assortative mating in animals. American Naturalist 181:E125-E138.

Keller, L., and K. G. Ross. 1998. Selfish genes: a green beard in the red fire ant. Nature 394:573-575.

Kendrick, K. M., M. R. Hinton, K. Atkins, M. A. Haupt, and J. D. Skinner. 1998. Mothers determine sexual preferences. Nature 395:229230.

Kirkpatrick, M. 1982. Sexual selection and the evolution of female choice. Evolution 36:1-12.

2001. Reinforcement during ecological speciation. Proceedings of the Royal Society B 268:1259-1263.

Kirkpatrick, M., and N. Barton. 1997. The strength of indirect selection on female mating preferences. Proceedings of the National Academy of Sciences of the USA 94:1282-1286.

Kirkpatrick, M., and S. L. Nuismer. 2004. Sexual selection can constrain sympatric speciation. Proceedings of the Royal Society B 271:687693.

Kirkpatrick, M., and V. Ravigné. 2002. Speciation by natural and sexual selection: models and experiments. American Naturalist 159(suppl.): S22-S35.

Kondrashov, A. S., and F. A. Kondrashov. 1999. Interactions among quantitative traits in the course of sympatric speciation. Nature 400: 351-354.

Kopp, M., and J. Hermisson. 2008. Competitive speciation and costs of choosiness. Journal of Evolutionary Biology 21:1005-1023.

Kronforst, M. R., L. G. Young, D. D. Kapan, C. McNeely, R. J. O’Neill, and L. E. Gilbert. 2006. Linkage of butterfly mate preference and wing color preference cue at the genomic location of wingless. Proceedings of the National Academy of Sciences of the USA 103:6575-6580.

Labonne, J., and A. P. Hendry. 2010. Natural and sexual selection giveth and taketh away reproductive barriers: models of population divergence in guppies. American Naturalist 176:26-39.

Lande, R. 1981. Models of speciation by sexual selection on polygenic traits. Proceedings of the National Academy of Sciences of the USA 78:3721-3725.

- 1982. Rapid origin of sexual isolation and character divergence in a cline. Evolution 36:213-223.

Levene, H. 1953. Genetic equilibrium when more than one ecological niche is available. American Naturalist 87:331-333.
Linn, C., J. L. Feder, S. Nojima, H. R. Dambroski, S. H. Berlocher, and W. Roelofs. 2003. Fruit odor discrimination and sympatric host race formation in Rhagoletis. Proceedings of the National Academy of Sciences of the USA 100:11490-11493.

Liou, L. W., and T. D. Price. 1994. Speciation by reinforcement of premating isolation. Evolution 48:1451-1459.

Löfstedt, C., B. Hansson, W. Roelofs, and B. Bengtsson. 1989. No linkage between genes controlling female pheromone production and male pheromone response in the European corn borer, Ostrinia nubilalis Hübner (Lepidoptera; Pyralidae). Genetics 123:553-556.

Lorch, P. D., S. Proulx, L. Rowe, and T. Day. 2003. Condition-dependent sexual selection can accelerate adaptation. Evolutionary Ecology Research 5:867-881.

Maan, M. E., and O. Seehausen. 2011. Ecology, sexual selection and speciation. Ecology Letters 14:591-602.

. 2012. Magic cues versus magic preferences in speciation. Evolutionary Ecology Research 14:779-785.

Mallet, J. 2008. Hybridization, ecological races and the nature of species: empirical evidence for the ease of speciation. Philosophical Transactions of the Royal Society B 363:2971-2986.

Marcillac, F., Y. Grosjean, and J.-F. Ferveur. 2005. A single mutation alters production and discrimination of Drosophila sex pheromones. Proceedings of the Royal Society B 272:303-309.

Mateo, J. M., and R. E. Johnston. 2000. Kin recognition and the armpit effect: evidence of self-referent phenotype matching. Proceedings of the Royal Society B 267:695-700.

Matessi, C., A. Gimelfarb, and S. Gavrilets. 2001. Long-term buildup of reproductive isolation promoted by disruptive selection: how far does it go? Selection 2:41-64.

Matsubayashi, K., S. Kahono, and H. Katakura. 2011. Divergent host plant specialization as the critical driving force in speciation between populations of a phytophagous ladybird beetle. Journal of Evolutionary Biology 24:1421-1432.

Maynard Smith, J. 1966. Sympatric speciation. American Naturalist 100:637-650.

Mays, H. L., and G. E. Hill. 2004. Choosing mates: good genes versus genes that are a good fit. Trends in Ecology and Evolution 19:554559.

McNiven, V. T., and A. J. Moehring. 2013. Identification of genetically linked female preference and male trait. Evolution 67:2155-2165.

Mendelson, T. C., M. D. Martin, and S. M. Flaxman. 2014. Mutationorder divergence by sexual selection: diversification of sexual signals in similar environments as a first step in speciation. Ecology Letters 17:1053-1066.

Merrill, R. M., B. Van Schooten, J. A. Scott, and C. D. Jiggins. 2011. Pervasive genetic associations between traits causing reproductive isolation in Heliconius butterflies. Proceedings of the Royal Society B 278: 511-518.

M'Gonigle, L. K., R. Mazzucco, S. P. Otto, and U. Dieckmann. 2012. Sexual selection enables long-term coexistence despite ecological equivalence. Nature 484:506-509.

Muller, H. J. 1942. Isolating mechanisms, evolution and temperature. Biological symposia. 6:71-125.

Norvaišas, P., and E. Kisdi. 2012. Revisiting Santa Rosalia to unfold a degeneracy of classic models of speciation. American Naturalist 180: 388-393.

Nosil, P. 2008. Speciation with gene flow could be common. Molecular Ecology 17:2103-2106.

2012. Ecological speciation. Oxford University Press, Cambridge, MA. 
O'Donald, P. 1960. Assortative mating in a population in which two alleles are segregating. Heredity 15:389-396.

Orr, H. A. 1995. The population genetics of speciation: the evolution of hybrid incompatibilities. Genetics 139:1805-1813.

Otto, S. P., M. Servedio, and S. Nuismer. 2008. Frequency-dependent selection and the evolution of assortative mating. Genetics 179:2091-2112.

Papadopulos, A. S., W. J. Baker, D. Crayn, R. K. Butlin, R. G. Kynast, I. Hutton, and V. Savolainen. 2011. Speciation with gene flow on Lord Howe Island. Proceedings of the National Academy of Sciences of the USA 108:13188-13193.

Payne, R. J., and D. C. Krakauer. 1997. Sexual selection, space, and speciation. Evolution 51:1-9.

Pennings, P. S., M. Kopp, G. Meszéna, U. Dieckmann, and J. Hermisson. 2008. An analytically tractable model of competitive speciation. American Naturalist 171:E44-E71.

Proulx, S. R. 2001. Female choice via indicator traits easily evolves in the face of recombination and migration. Evolution 55:2401-2411.

Prum, R. O. 2010. The Lande-Kirkpatrick mechanism is the null model of evolution by intersexual selection: implications for meaning, honesty, and design in intersexual signals. Evolution 64:3085-3100.

Ratterman, N. L., G. G. Rosenthal, G. E. Carney, and A. G. Jones. 2014. Genetic variation and covariation in male attractiveness and female mating preferences in Drosophila melanogaster. G3: Genes, Genomes, Genetics 4:79-88.

Reinhold, K. 2004. Modeling a version of the good-genes hypothesis: female choice of locally adapted males. Organisms, Diversity, and Evolution 4:157-163.

Reinhold, K., and H. Schielzeth. 2015. Choosiness, a neglected aspect of preference functions: a review of methods, challenges and statistical approaches. Journal of Comparative Physiology A 201:171-182.

Rettelbach, A., M. Kopp, U. Dieckmann, and J. Hermisson. 2013. Three modes of adaptive speciation in spatially structured populations. American Naturalist 182:E215-E234.

Rice, W. R., and E. E. Hostert. 1993. Laboratory experiments on speciation: what have we learned in 40 years? Evolution 47:1637-1653.

Ripa, J. 2009. When is sympatric speciation truly adaptive? an analysis of the joint evolution of resource utilization and assortative mating. Evolutionary Ecology 23:31-52.

Rodríguez, R. L., K. Ramaswamy, and R. B. Cocroft. 2006. Evidence that female preferences have shaped male signal evolution in a clade of specialized plant-feeding insects. Proceedings of the Royal Society B 273:2585-2593.

Roelofs, W., T. Glover, X.-H. Tang, I. Sreng, P. Robbins, C. Eckenrode, C. Löfstedt, B. S. Hansson, and B. O. Bengtsson. 1987. Sex pheromone production and perception in European corn borer moths is determined by both autosomal and sex-linked genes. Proceedings of the National Academy of Sciences of the USA 84:7585-7589.

Rolshausen, G., G. Segelbacher, K. A. Hobson, and H. M. Schaefer. 2009. Contemporary evolution of reproductive isolation and phenotypic divergence in sympatry along a migratory divide. Current Biology 19:2097-2101.

Rundle, H. D., and P. Nosil. 2005. Ecological speciation. Ecology Letters 8:336-352.

Safran, R. J., E. S. Scordato, L. B. Symes, R. L. Rodríguez, and T. C. Mendelson. 2013. Contributions of natural and sexual selection to the evolution of premating reproductive isolation: a research agenda. Trends in Ecology and Evolution 28:643-650.

Schindler, S., O. Breidbach, and J. Jost. 2013. Preferring the fittest mates: an analytically tractable model. Journal of Theoretical Biology $317: 30-38$.
Schluter, D. 2009. Evidence for ecological speciation and its alternative. Science 323:737-741.

Schneider, K., and R. Bürger. 2006. Does competitive divergence occur if assortative mating is costly? Journal of Evolutionary Biology 19:570-588.

Scordato, E. S., L. B. Symes, T. C. Mendelson, and R. J. Safran. 2014. The role of ecology in speciation by sexual selection: a systematic empirical review. Journal of Heredity 105:782-794.

Servedio, M. R. 2000. Reinforcement and the genetics of nonrandom mating. Evolution 54:21-29.

- 2004. The evolution of premating isolation: local adaptation and natural and sexual selection against hybrids. Evolution 58:913-924.

- 2009. The role of linkage disequilibrium in the evolution of premating isolation. Heredity 102:51-56.

. 2011. Limits to the evolution of assortative mating by female choice under restricted gene flow. Proceedings of the Royal Society B 278:179-187.

2016. Geography, assortative mating, and the effects of sexual selection on speciation with gene flow. Evolutionary Applications 9:91-102.

Servedio, M. R., and J. W. Boughman. 2017. The role of sexual selection in local adaptation and speciation. Annual Review of Ecology, Evolution, and Systematics 48:85-109.

Servedio, M. R., and R. Bürger. 2014. The counterintuitive role of sexual selection in species maintenance and speciation. Proceedings of the National Academy of Sciences of the USA 111:8113-8118.

- 2015. The effects of sexual selection on trait divergence in a peripheral population with gene flow. Evolution 69:2648-2661.

Servedio, M. R., and M. A. Noor. 2003. The role of reinforcement in speciation: theory and data. Annual Review of Ecology, Evolution, and Systematics 34:339-364.

Servedio, M. R., G. S. Van Doorn, M. Kopp, A. M. Frame, and P. Nosil. 2011. Magic traits in speciation: "magic" but not rare? Trends in Ecology and Evolution 26:389-397.

Sharma, M., A. Wilson, and D. Hosken. 2016. Fisher's sons' effect in sexual selection: absent, intermittent or just low experimental power? Journal of Evolutionary Biology 29:2464-2470.

Shaw, K. L., and S. C. Lesnick. 2009. Genomic linkage of male song and female acoustic preference QTL underlying a rapid species radiation. Proceedings of the National Academy of Sciences of the USA 106: 9737-9742.

Smadja, C. M., and R. K. Butlin. 2011. A framework for comparing processes of speciation in the presence of gene flow. Molecular Ecology 20:5123-5140.

Stelkens, R. B., M. E. Pierotti, D. A. Joyce, A. M. Smith, I. van der Sluijs, and O. Seehausen. 2008. Disruptive sexual selection on male nuptial coloration in an experimental hybrid population of cichlid fish. Philosophical Transactions of the Royal Society B 363:2861-2870.

Takimoto, G., M. Higashi, and N. Yamamura. 2000. A deterministic genetic model for sympatric speciation by sexual selection. Evolution 54:1870-1881.

Ten Cate, C., M. N. Verzijden, and E. Etman. 2006. Sexual imprinting can induce sexual preferences for exaggerated parental traits. Current Biology 16:1128-1132.

Ten Cate, C., and D. R. Vos. 1999. Sexual imprinting and evolutionary processes in birds: a reassessment. Advances in the Study of Behavior 28:1-31.

Thibert-Plante, X., and S. Gavrilets. 2013. Evolution of mate choice and the so-called magic traits in ecological speciation. Ecology Letters 16:1004-1013. 
Tramm, N. A., and M. R. Servedio. 2008. Evolution of mate-choice imprinting: competing strategies. Evolution 62:1991-2003.

Turner, G. F., and M. T. Burrows. 1995. A model of sympatric speciation by sexual selection. Proceedings of the Royal Society B 260: 287-292.

Udovic, D. 1980. Frequency-dependent selection, disruptive selection, and the evolution of reproductive isolation. American Naturalist 116:621-641.

Ueshima, R., and T. Asami. 2003. Evolution: single-gene speciation by left-right reversal. Nature 425:679.

van Doorn, G. S., U. Dieckmann, and F. J. Weissing. 2004. Sympatric speciation by sexual selection: a critical reevaluation. American Naturalist 163:709-725.

van Doorn, G. S., P. Edelaar, and F. J. Weissing. 2009. On the origin of species by natural and sexual selection. Science 326:1704-1707.

van Doorn, G. S., and F. J. Weissing. 2002. Ecological versus sexual selection models of sympatric speciation: a synthesis. Selection 2:17-40.

Veen, T., and S. Otto. 2015. Liking the good guys: amplifying local adaptation via the evolution of condition-dependent mate choice. Journal of Evolutionary Biology 28:1804-1815.

Verzijden, M. N., R. F. Lachlan, and M. R. Servedio. 2005. Female matechoice behavior and sympatric speciation. Evolution 59:2097-2108.

Verzijden, M. N., and C. Ten Cate. 2007. Early learning influences species assortative mating preferences in Lake Victoria cichlid fish. Biology Letters 3:134-136.

Verzijden, M. N., C. Ten Cate, M. R. Servedio, G. M. Kozak, J. W. Boughman, and E. I. Svensson. 2012. The impact of learning on sexual selection and speciation. Trends in Ecology and Evolution 27: 511-519.

Verzijden, M. N., J. Zwinkels, and C. Ten Cate. 2009. Cross-fostering does not influence the mate preferences and territorial behaviour of males in lake victoria cichlids. Ethology 115:39-48.
Webster, S. E., J. Galindo, J. W. Grahame, and R. K. Butlin. 2012. Habitat choice and speciation. International Journal of Ecology 2012: 154686.

Weissing, F. J., P. Edelaar, and G. S. Van Doorn. 2011. Adaptive speciation theory: a conceptual review. Behavioral Ecology and Sociobiology 65:461-480.

Weissman, D. B., K. A. Judge, S. C. Williams, D. W. Whitman, and V. F. Lee. 2008. Small-male mating advantage in a species of Jerusalem cricket (Orthoptera: Stenopelmatinae: Stenopelmatus). Journal of Orthoptera Research 17:321-332.

Wiley, C., C. K. Ellison, and K. L. Shaw. 2012. Widespread genetic linkage of mating signals and preferences in the Hawaiian cricket Laupala. Proceedings of the Royal Society B 279:1203-1209.

Wiley, C., and K. L. Shaw. 2010. Multiple genetic linkages between female preference and male signal in rapidly speciating Hawaiian crickets. Evolution 64:2238-2245.

Wood, T. K. 1980. Divergence in the Enchenopa binotata Say complex (Homoptera: Membracidae) effected by host plant adaptation. Evolution 34:147-160.

1993. Speciation of the Enchenopa binotata complex (Insecta: Homoptera: Membracidae). Pages 299-317 in D. R. Lees and D. Edwards, eds. Evolutionary patterns and processes. Vol. 14. Academic Press, New York.

Yeh, D. J., and M. R. Servedio. 2015. Reproductive isolation with a learned trait in a structured population. Evolution 69:1938-1947. Zimmer, C., and D. J. Emlen. 2013. Evolution: making sense of life. Roberts, Greenwood Village, CO.

Associate Editor: Roger K. Butlin Editor: Yannis Michalakis

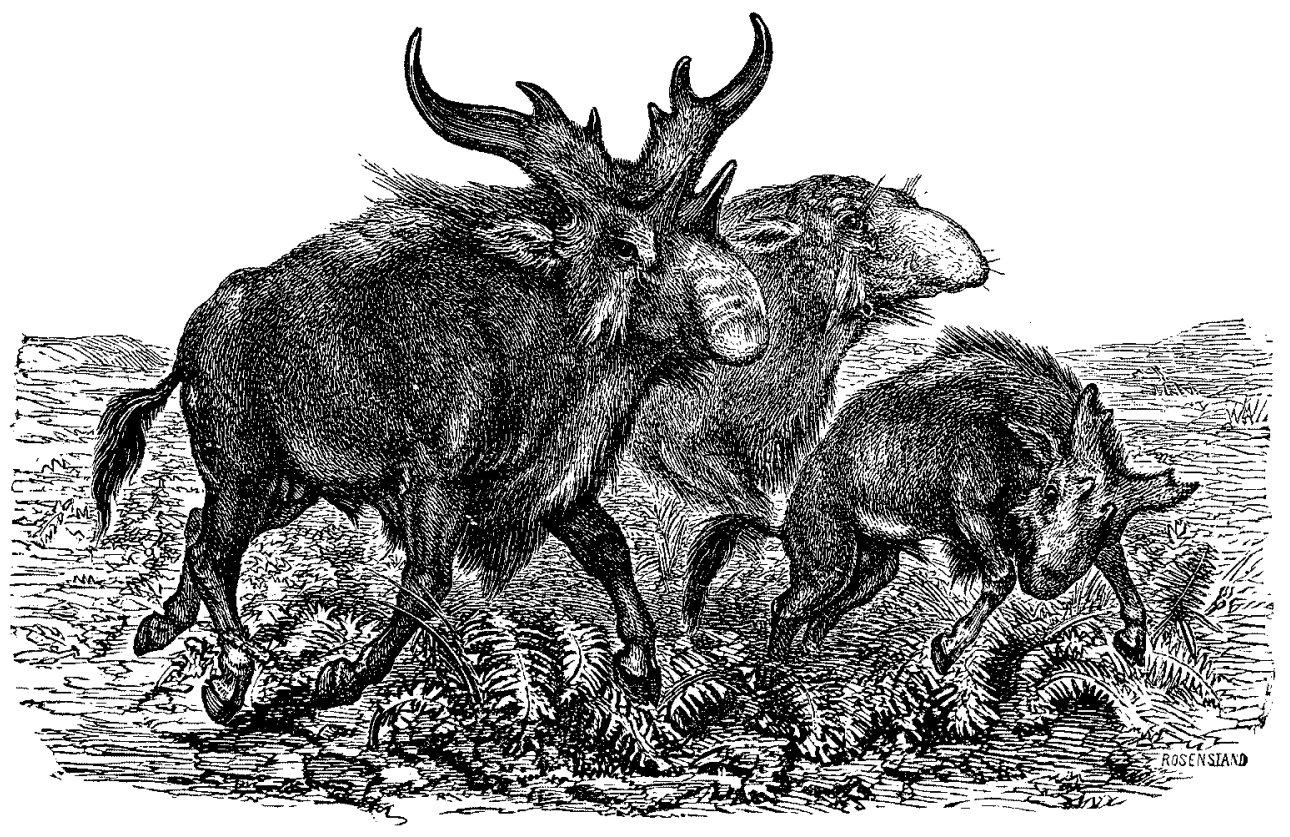

\footnotetext{
"Most of our readers have probably never met with the accompanying figures restoring the gigantic ruminant of the Himalayas, which we copy from the Danish Tidsskrift. This was a Tertiary, probably Miocene, 'elephantine stag, having four horns and probably a long proboscis. . . It is supposed to have had the bulk of an elephant and greater height." "From the notice "Restoration of the Sivatherium" in the "Zoölogy" section (The American Naturalist, 1877, 11:435-436).
} 